\title{
Crustal structure of the SW-Moroccan margin from wide-angle and reflection seismic data (the DAKHLA experiment) Part A: Wide-angle seismic models
}

\author{
F. Klingelhoefer ${ }^{a},{ }^{\star}$, C. Labails ${ }^{a},{ }^{b}$, E. Cosquer ${ }^{a}$, S. Rouzo ${ }^{a},{ }^{c}$, L. Gélia ${ }^{a}$, D. Aslanian ${ }^{a}$, J.-L. \\ Olivet $^{a}$, M. Sahabi ${ }^{d}$, H. Nouzé ${ }^{a}$ and P. Unternehr ${ }^{\mathrm{e}}$
}

\footnotetext{
a Laboratory of Marine Geophysics and Geodynamics, Ifremer, B.P. 70, F-29280, Plouzané, France

${ }^{b}$ Geodynamics, NGU - Geological Survey of Norway, Leiv. Eirikssons vei, 39, N-7491 Trondheim, Norway

c Institut du Physique du Globe Paris, France

${ }^{\mathrm{d}}$ Faculté des Sciences, University of El Jadida, BP 20, 24000 El Jadida, Maroc, Morocco

e Total, Exploration-Production, Geosciences, place de la Coupole La defense 6, 92078 Paris La Defense, France
}

*: Corresponding author : F. Klingelhoefer, Tel.: +33 2982242 21, email address: Frauke.Klingelhoefer@ifremer.fr

\begin{abstract}
:
A total $1500 \mathrm{~km}$ of seismic reflection and wide-angle profiles were acquired off the southern Moroccan margin during the DAKHLA cruise, a joint project of Ifremer, the Universities of Brest, El Jadida and Lisbon and Total. The shots along two profiles parallel to the margin and two profiles perpendicular to the margin were also recorded by ocean bottom seismometers (OBS). The profiles perpendicular to the margin were additionally extended on land using 14 stations on the northern profile and 11 stations on the southern profile.

Modelling of the reflection and wide-angle seismic data reveals a $10 \mathrm{~km}$ deep sedimentary basin including two high velocity carbonate layers. Lateral crustal thinning is observed from a $27 \mathrm{~km}$ thick crystalline continental crust to a $7 \mathrm{~km}$ thick oceanic crust occurring over less than $100 \mathrm{~km}$. The crystalline continental crust can be divided into two distinct layers of 12 and $15 \mathrm{~km}$ thickness. The oceanic crust east of the magnetic anomaly M25 displays higher velocities in layer 3 than west of the magnetic anomaly. The change in seismic velocity suggests a possible link to changes in accretionary processes of the oceanic crust. Some regions show seismic velocities between 6.8 and $7.4 \mathrm{~km} / \mathrm{s}$ which could be explained by slightly elevated mantle temperatures during accretion of the crust.
\end{abstract}

Keywords: Southern Moroccan margin; Keyword wide-angle seismic; Ocean continent transition

\section{Introduction}

The study of passive continental margins is of importance for understanding the processes of rifting and margin formation and the evolution of associated sedimentary basins. Combined wide-angle and deep seismic reflection data provide information about the deep crustal structure of the margin as well as the stratigraphic sequence of the basins. Together these data can be used to quantify extension in the upper and lower crust, determine the degree of symmetry of rift structures and thus address fundamental questions concerning 
the mechanisms of rifting (e.g. McKenzie, 1978; Wernicke, 1985; Whitmarsh et al., 2001) .

Two refraction seismic surveys were carried out on the central Moroccan and Mauritanian continental margin. A refraction seismic profile from the Mauritanian continental shelf to the Cape Verde Rise shows a Moho depth decreasing from $30 \mathrm{~km}$ at the continental part to $18 \mathrm{~km}$ beneath the oceanic crust, a $4-5$ $\mathrm{km}$ thick carbonate platform at the continental slope and a sedimentary basin up to $10 \mathrm{~km}$ thick at the continent ocean transition zone (Weigel et al., 1982) (Figure 1).

A similar sequence of high seismic velocity carbonates and salt diapirs underlying a thick sedimentary cover has been imaged off the central moroccan continental margin by modelling of sonobuoy data (Hinz et al., 1982) (Figure 1). These layers overlie a thinned continental type crust intruded by basaltic bodies. It was proposed that the distinct western boundary of the Moroccan diapir province marks the zone where the actual separation of Morroco and Nova Scotia occurred (Hinz et al., 1982). In this region some landward dipping reflectors have been interpreted as volcanic products which might be associated to magnetic anomalies found on the margin (Maillard et al., 2006).

Interpretation of a $440 \mathrm{~km}$ long wide-angle and reflection seismic profile from the Sismar cruise perpendicular to the Moroccan margin at $33-34^{\circ} \mathrm{N}$, extending from nearly normal oceanic crust in the vicinity of Coral Patch Seamount to the coast at El Jadida and about $130 \mathrm{~km}$ inland revealed crustal thinning from $35 \mathrm{~km}$ beneath the continent to about $7 \mathrm{~km}$ at the western end of the profile (Contrucci et al., 2004) (Figure 1). The thinned continental crust underlies a thick sedimentary cover which is locally perturbed by salt tectonics 
and reverse faulting. The region of thinned crust is about $50 \mathrm{~km}$ wide and marks the transition from continental crust to normal oceanic crust, but this domain does not exhibit the anomalously high p-wave velocities typically associated with serpentinised upper mantle and typically found on non-volcanic margins.

The easternmost magnetic anomaly (S1) off the Moroccan margin has been identified on a magnetic anomaly map constructed from a compilation of magnetic data of seven geophysical surveys. This anomaly has been correlated to the initial opening of the Atlantic ocean (Roeser, 1982; ?) and therefore represents the counterpart to the East Coast Magnetic Anomaly off the U. S. coast (see Figure 1). A $100 \mathrm{~km}$ wide transitional crust was detected from refraction seismic and gravity modelling east of the S1 magnetic anomaly (Roeser, 1982; Weigel et al., 1982). The authors propose that the magnetic pattern origininates from small intrusions into a crust originally of continental nature (Roeser, 1982).

The oceanic crust west of the S1 anomaly was accreted during the Jurassic magnetic quiet time. Modelling of existing weak magnetic anomalies in this region indicates a half spreading rate of about $2.2 \mathrm{~cm} / \mathrm{a}$ during the breakup (Roeser et al., 2002), although the authors cannot exclude slower values. Extrapolation of the weak anomalies back to the slope anomaly S1 then results in a breakup age of 170 Ma. A new interpretation of the S1 anomaly and the position of the salt basins of Morocco and Nova Scotia indicates a age of 190-195 Ma (Sahabi, 2004; Sahabi et al., 2004).

During the DAKHLA cruise a total of $1500 \mathrm{~km}$ of reflection seismic data were acquired. Two different marine seismic sources were used during the cruise. 
For the deep crustal targets a large $\left(8100 \mathrm{in}^{3}\right)$ airgun array was used in the single bubble mode (Avedik et al., 1993) consisting of 12 airguns between 250 $\mathrm{in}^{3}$ and $976 \mathrm{in}^{3}$ (16 litres). The airgun array was shot at a constant interval of $150 \mathrm{~m}$. On the thinner oceanic crust a smaller airgun array ("Bulle") (4545 in ${ }^{3}$ ) was used, consisting of 12 airguns between $105 \mathrm{in}^{3}$ and $976 \mathrm{in}^{3}$ to allow a finer resolution of the sedimentary and crustal structures. A total of 10800 shots of both airgun constellations were recorded on 15 Ifremer ocean bottom seismometers (OBS) and 3 OBS of the University of Lisbon, as well as on the 4.5-km-360-channel digital-streamer of Ifremer. All 60 OBS deployments yielded usable data. The marine shots were additionally successfully recorded by 14 landstations (HATHOR Leas) of the network of the INSU (Institut National des Sciences de l'Univers). In shallow water depths $(<100 \mathrm{~m})$ the aigun array was towed at a more shallow depth and tuned to the first peak. The shot interval was about 2 minutes to reduce the noise caused by the previous shot in the recordings. For safety reasons the streamer was not deployed and these shots were recorded by OBS and landstations only. To constrain the shallow sedimentary structures and the depth to basement beneath the landstation a vibroseis survey was conducted simulateously (Fateh, 2003). All OBS, streamer and landstation data were recorded using a $4 \mathrm{~ms}$ sample interval.

One aim of the DAKHLA experiment was to provide complete crustal sections along and across the ocean-continent boundary in order to image any underplating and/or seaward dipping reflectors, as well as to constrain the nature of the crust in the transition zone (Figure 1). Two parallel profiles were shot to sample the lateral variability of the margin. One margin perpendicular profile was extended $200 \mathrm{~km}$ out onto oceanic crust to seek for possible explanations 
for the change of the roughness of the oceanic crust around anomaly M25 and to image possible related changes in the nature of the crust. An additional objective was to investigate origin of the West African Magnetic Anomaly (WACMA or S1) along this part of the margin.

This part of our study focusses on the wide-angle seimic modelling, while the second part describes geological constraints and tectonic heritage of this region found from our dataset (Labails et al., 2007).

\section{Data quality and processing}

All OBS data were corrected for the clock drift during the deployment. The individual time drifts were between 0 and $7 \mathrm{~ms}$ per day with a mean of 2.86 ms. Instrument locations were corrected for drift from the deployment position during their descent to the seafloor using the direct water wave arrival. Instruments in water depth less than $100 \mathrm{~m}$ where not corrected as the expected drift is small. Furthermore instruments that recorded no close shots were not corrected, if no direct water wave arrival could be picked as a first arrival. The drift of the instruments even in deep water never exceeded $100 \mathrm{~m}$. Picking of the onset of first and later arrivals was performed without filtering where possible, to avoid time errors. When necessary, different filters were applied to the data. Arrivals from longer offsets are of lower frequency compared to short offset arrivals, so the filter frequencies were chosen appropriately.

Processing of the multichannel seismic data on board was performed using the Geovecteur processing package. It included spherical divergence correction, FK-filtering, bandpass filtering (3-5-50-60 Hz), internal mute and dynamic cor- 
rections. Velocity analysis was performed every 200 CDP for the final stack. The last processing steps included applying an automatic gain control and a Kirchoff migration using water or stacking velocities. Arrival times of the main sedimentary layers and basement were picked from the reflection seismic data. These were converted to depth using the OBS data, which were in good agreement with seismic velocities from velocity analysis of the reflection seismic data. The depth and velocities of the crustal layers and the upper mantle were modelled from the OBS data only.

Data quality is very good on the oceanic part of the northern profile (Profile Nord) (Figure 2). Useful arrivals could be picked up to $120 \mathrm{~km}$ source receiver offset, including arrivals reflected from the Moho and upper mantle. The carbonate platform at the continental shelf includes two major velocity inversions and thus renders seismic energy penetration and modelling more difficult (Figure 3). Due to the very shallow water depth, the easternmost instruments show high amplitude noise at short offsets. Longer offsets are of relatively better quality, including arrivals from the Moho and upper mantle (Figure 4). The landstations positioned on the prolongation of the marine profile yield very high quality data, with clear lower crustal and upper mantle arrivals (Figure 5).

On Profile Sud the data quality is comparable to that on Profile Nord (Figure 6) generally improving towards the oceanic part. Profile GH, located on thin crust and undisturbed sediments, exhibits very good data quality with clear PmP and Pn arrivals on every station (Figure 7). Data quality along Profile $\mathrm{EF}$ is equally good, although the disturbed sediments render interpretation and modelling of the profile slightly more difficult (Figure 8). 


\section{$3 \quad$ Velocity modelling}

The data were modelled using the inversion and ray tracing algorithm of Zelt and Smith (1992). Modelling was performed using a layer-stripping approach, proceeding from the top of the structure towards the bottom. Upper layers, where not directly constrained by arrivals from within the layer, were adjusted to improve the fit of lower layers. Velocity gradients and the phase identification in the velocity model were further constrained by synthetic seismogram modelling using the finite-element method (Cohen and Stockwell, 2003; Stockwell, 1999).

The seafloor bathymetry was taken from the multibeam data where possible and otherwise from the echo sounder data corrected for the water velocity. On land topography was included from the altimetry measurements at each landstation. Arrival times of the main sedimentary layers and basement were picked from the reflection seismic data (Figure 17) and included into the modelling at a lateral interval between 0.5 and $2.5 \mathrm{~km}$, depending on the topography and depth of the layer using velocity picks from the OBS data analysis directly without building 1D velocity models first. Node interval in the deeper layers was chosen between 5 and $10 \mathrm{~km}$, as the low frequency seismic waves (5-15 $\mathrm{Hz}$ ) and OBS spacing will not allow a finer resolution on deep interfaces. All models represent a minimum structure modelling approach and care was taken not to include lateral velocity changes or layer topography changes where not required by the data.

All four models are composed of 9 different layers: the water layer, 4 sedimentary layers, two high-velocity layers embedded within the sedimentary section, 
two crustal layers and the upper mantle layer (figure 9). Each layer is defined by depth and velocity nodes. Water velocity is a constant $1.52 \mathrm{~km} / \mathrm{s}$ on the profiles perpendicular to the margin and $1.51 \mathrm{~km} / \mathrm{s}$ on the profiles parallel to the margin. Node spacing of the seafloor and sedimentary layers was 2.0 $\mathrm{km}$ for the Profiles Sud, GH and EF reflecting the higher resolution of the reflection seismic data. Node spacing was chosen to be $2.5 \mathrm{~km}$ on Profile Nord to avoid numerical instabilities on this very long profile. For the crustal layers the node distance varies between 2.5 and $10 \mathrm{~km}$ depending on the depth of the interface.

Seismic velocities in the sedimentary layers vary on the upper layer boundary and lower layer boundary between $1.8-2.2 \mathrm{~km} / \mathrm{s}, 2.8-3.2 \mathrm{~km} / \mathrm{s}, 3.0-3.20$ and $4.0-4.90 \mathrm{~km} / \mathrm{s}$ on Profile Nord. Between 400 and $550 \mathrm{~km}$ model offset, two layers with considerably higher velocities are found within the sedimentary section. They represent high velocity layers with a velocity inversion at their base. As no seismic energy returns from the underlying low velocity zone this inversion produces a characteristic stepback in the first arrivals (Figure 3). The two layers are modelled using a velocity of $3.9-4.1 \mathrm{~km} / \mathrm{s}$ and $4.8-5.2$ $\mathrm{km} / \mathrm{s}$. The model comprises two distinct igneous crustal layers. The upper layer shows velocities between $5.5-6.0 \mathrm{~km} / \mathrm{s}$ in the western part and 6.0-6.2 $\mathrm{km} / \mathrm{s}$ on the eastern part of the profile. The lower layer is characterised by with velocities between 6.6 and as high as $7.4 \mathrm{~km} / \mathrm{s}$ in some parts of the model. Upper mantle velocities are constrained to $8.0-8.2 \mathrm{~km} / \mathrm{s}$ by diving waves into the mantle.

Sedimentary velocities on the parallel Profile Sud are very similar to Profile Nord, between $2.0-2.2 \mathrm{~km} / \mathrm{s}, 2.8-3.0 \mathrm{~km} / \mathrm{s}, 3.0-3.20 \mathrm{~km} / \mathrm{s}$ and $4.0-4.5$ $\mathrm{km} / \mathrm{s}$. The two high velocity layers were modelled using velocities between 4.2 
- $4.4 \mathrm{~km} / \mathrm{s}$ and $3.9-4.1 \mathrm{~km} / \mathrm{s}$. Lower crustal velocities change from 7.0 - 7.4 $\mathrm{km} / \mathrm{s}$ to $6.5-6.8 \mathrm{~km} / \mathrm{s}$ as on Profile Nord. Finally the upper mantle velocity was constrained to be 8.0 to $8.2 \mathrm{~km} / \mathrm{s}$ along the entire model profile.

On the margin parallel Profile GH and EF water depth and crustal thickness show less variation than on the longer profiles perpendicular to the margin (Figure 9). On Profile GH water depth is around $2.5 \mathrm{~km}$ and the sedimentary thickness around $8 \mathrm{~km}$. Sedimentary velocities range from $2.2-2.4 \mathrm{~km} / \mathrm{s}, 2.8$ $3.4 \mathrm{~km} / \mathrm{s}, 3.6-3.8 \mathrm{~km} / \mathrm{s}$ and $4.4-4.6 \mathrm{~km} / \mathrm{s}$. The upper crustal velocities vary between 5.80 and $6.00 \mathrm{~km} / \mathrm{s}$ and the lower crustal velocities are between 6.5 $7.3 \mathrm{~km} / \mathrm{s}$ along the entire profile. Upper mantle velocities are constrained by Pn arrivals to be $8.0-8.2 \mathrm{~km} / \mathrm{s}$.

Profile EF is located parallel to Profile GH about $30 \mathrm{~km}$ closer to the coastline. The sedimentary velocities range between $2.2-2.4 \mathrm{~km} / \mathrm{s}, 2.8-3.4 \mathrm{~km} / \mathrm{s}, 3.6$ - $4.0 \mathrm{~km} / \mathrm{s}$ and $4.4-4.8 \mathrm{~km} / \mathrm{s}$, slightly higher than on Profile GH. The lower crustal velocities vary from $6.9-7.20$ at the northern end to $7.20-7.40$ at the southern end of the Profile. No Pn arrivals were detected on this profile so an upper mantle velocity of $8.0-8.2 \mathrm{~km} / \mathrm{s}$ is inferred from the crossing profiles.

\section{Error analysis}

Picking uncertainties for each phase were defined using the method of Zelt (1999) by the ratio of the amplitudes $250 \mathrm{~ms}$ before and after onset of the picked arrival. The picking error of a pick on a noisy trace displaying a low ratio of amplitude before and after the onset of the arrival will be larger than the picking error of a pick on a trace with a large ration of amplitude before 
and after the onset of the arrival. A mean error was calculated from all picks for each phase of each station and then converted to predicted travel-time picking errors between 20 and 125 ms using the table of (Zelt, 1999). Using this procedure the final chi-square travel-time error of all modelled travel-time picks should be close to 1.0 ensuring a good quality of the fit of the model without over interpretation of arrivals on traces with a low signal to noise ratio. All arrivals on the landstation data were assigned a picking error of 100 ms, to take into account the unreversed nature of the shots on land even at high signal-to noise ratios. The number of picks, RMS traveltime residual and the $\chi^{2}$-error for all phases are listed in Table 1 to 4 .

Two-point ray-tracing between source and receiver (Figures 10, 11, 12 and 13) shows well resolved and unconstrained areas. Ray coverage is generally very good on all profiles. On Profile Nord the sedimentary layers and upper basement are well resolved throughout the model (Figure 10). Fewer reflected rays are seen from the middle crustal and Moho discontinuity. The third sedimentary layer on Profile Nord is not covered between 400 and $500 \mathrm{~km}$ model offset, as it represents a low velocity zone. Velocities have been inferred to be constant in this area. No rays cover the sedimentary and shallow crustal layers beneath the landstations, however results from the Vibroseis survey are in good agreement with a shallow sedimentary basin and an upper crustal velocity of $6.2 \mathrm{~km} / \mathrm{s}$ as found from the OBS modelling. Ray coverage is very good on Profile Sud as well, except again for the third sedimentary layer, which represents a low velocity zone (Figure 11). For Profile GH the ray coverage is sufficient, but slightly lower due to the sparser instrument spacing on this profile (Figure 12). Ray coverage on Profile EF is higher then on Profile GH especially in the lower crustal layers (Figure 13). However, no rays penetrat- 
ing the upper mantle have been modelled. For all lines the Moho has been additionally constrained in those areas of insufficient ray coverage by gravity modelling. Figure 14 shows ray-coverage for some individual stations.

Additional information about the quality of the velocity model can be gained from the resolution parameter (see Figure 15) (Zelt and Smith, 1992). Resolution is a measure of the number of rays passing through a region of the model constrained by one particular velocity node and is therefore dependent on the node spacing. Layers with a low number of nodes can be well constrained by relatively few rays passing through the layer, while layers including many velocity nodes need rays passing through each node. Nodes with values greater than 0.5 , corresponding to white and yellow areas in the model are considered well resolved (Figure 15). Only few regions of the profiles show a resolution less than 0.5, which is considered unsufficiently resolved, and is marked in red. Along most profiles, the third sedimentary layer is slightly less well resolved (between 0.5-0.9) where it represents a low velocity zone. The upper mantle velocity at model offsets larger than $600 \mathrm{~km}$ on Profile $\mathrm{N}$ is not well resolved $(<0.5)$, as no rays penetrate to the mantle in this region. Finally the lower crustal layer at model offsets larger than $120 \mathrm{~km}$ is not sufficiently well resolved $(<0.5)$ on profile EF. However, reducing the number of velocity nodes does not allow a proper fit to the travel times.

The fit between predicted arrivals times and travel-time picks provides information about the quality of the model (Figures 10, 11, 12 and 13). The $\chi^{2}$ is defined as the root-mean-square traveltime misfit between observed and calculated arrivals normalised to the picking uncertainty. The number of picks, picking error, the values for the $\chi^{2}$ parameter and the rms misfit for the most important phases of the models are listed in Table 1, 2, 3 and 4 . The final 
models are of minimum structure.

\section{$5 \quad$ Gravity modelling}

Since seismic velocities and known densities for oceanic crust are well-correlated (Ludwig et al., 1970), gravity modelling provides an important additional constraint on the seismic model. Areas unconstrained by the seismic data can be modelled by comparing calculated gravity anomalies with those observed. The gravity data were forward modelled using the gravity module of the software of Zelt and Smith (1992). To avoid edge effects both models were extended by $100 \mathrm{~km}$ at both ends and down to a depth of $95 \mathrm{~km}$. The calculated anomalies can be compared to the gravity field from satellite altimetry (Figure 16).

Average P-wave velocities for all sedimentary layers of the seismic models were converted to densities using the of Ludwig, Nafe and Drake [1970] . Upper mantle densities were set to a constant $3.32 \mathrm{~g} / \mathrm{cm}^{3}$. Conversion of the lower crustal layers using one single velocity-density relationship proved insufficient. Using a comparatively low density for the high velocity oceanic crust (between 150 and $300 \mathrm{~km}$ model distance on Profile Nord) and a slightly elevated density for the crust in the transitional zone (360 to $480 \mathrm{~km}$ model distance on Profile Nord) substantially improved the fit of the models (Figure 16). However gravity modelling is non-unique and other models including normal density crust and a temperature anomaly in the upper mantle might provide a similar fit the data. Both profiles perpendicular to the margin show the largest mistfit at the end of the profile. This might be an edge effect of the modelling. 


\section{Comparison to reflection seismic data}

The wide-angle seismic models converted to two-way travel-time models show good agreement with the reflection seismic data sections (Figure 17), but some additional layering in the sedimentary section is imaged by the reflection seismics. Sedimentary reflectors were taken from the reflection seismic sections converted to depth using velocities from the OBS and included into the model. However, only reflectors discernible in the OBS data and therefore necessary for the modelling were included to avoid over-parametrization of the inversion.

On all reflection seismic profiles, six main sedimentary layers were identified and included into the model. On Profile Nord at distances greater than 200 $\mathrm{km}$ from the coast, two sedimentary layers are pinching out as the total sedimentary thickness decreases. The margin parallel profile EF shows strong undulations in the sedimentary layers (Figures 9 and 17). The corresponding layers on Profile GH show less undulating surfaces. Sedimentary layers close to Tropical Seamount show strong perturbations, due to the activity of the volcano. Depth of the acoustic basement is in very good agreement along the entire model.

The character of the basement reflector changes along Profile Nord and Sud. On oceanic crust west of the M25 magnetic anomaly the basement shows a rough topography with highs and troughs of about $20 \mathrm{~km}$ length (Figure $18 \mathrm{~A}$ ). The oceanic basement east of the M25 magnetic anomaly is very smooth and prominent westward dipping reflectors are discernible cutting across the entire crust (Figure $18 \mathrm{~B}$ ). At 350 to $500 \mathrm{~km}$ model distance the basement shows a blocky character, characteristic of thinned continental crust (Figure $18 \mathrm{C}$ ). 
The mid-crustal discontinuity and the Moho reflector were modelled using the OBS arrivals only. However the oceanic Moho discontinuity, from wide-angle seismic data modelling converted to two-way travel-time, corresponds to the base of a series of reflectors in the corresponding reflection seismic section (Figure 18).

\section{Results and discussion}

Along Profile Nord the sedimentary section thickens from $2.5 \mathrm{~km}$ thickness at the western end of the profile to up to $9 \mathrm{~km}$ around $490 \mathrm{~km}$ model distance. It then thins rapidly towards the shoreline where basement crops out. The sedimentary sections comprise two high velocity layers of $3.2-3.4$ and $4.7-4.9 \mathrm{~km} / \mathrm{s}$ identified by a step-back in the wide-angle data set. These layers may either represent carbonate layers or volcanic extrusives. On Profile EF the upper sedimentary layers show a characteristic undulation of the surface at a wavelength of about $20 \mathrm{~km}$. These undulations might be due to contourite streams along the continental slope. Sedimentary layers on Profile $\mathrm{GH}$, situated about $30 \mathrm{~km}$ further away from the contental slope show similar undulations, but to a lesser degree.

The crustal structure of the margin is imaged by the four wide-angle and reflection seismic profiles and consists of five main regions (Figure 19), which can be distinguished by their seismic velocity structure, the nature of the basement and their density structure. They consist of (1) unthinned continental crust (2) a region of crustal thinning (3) a region crust of unknown composition and

(4) oceanic crust with high lower crustal velocities and smooth basement (5) normal oceanic crust. 
The unthinned continental crust is modelled by two layers of roughly similar thickness (12 and $15 \mathrm{~km}$ ) exhibiting velocities of $6.00-6.20$ and 6.50 - $6.80 \mathrm{~km} / \mathrm{s}$. The thickness of the unthinned crust modelled by unreversed landstation arrivals is about $27 \mathrm{~km}$. Such velocities and crustal thickness are characteristic of continental crust in this region (Hinz et al., 1982; Makris et al., 1985).

At the continental slope the crust thins from $27 \mathrm{~km}$ to about $8 \mathrm{~km}$ in a region of less than $100 \mathrm{~km}$ width (Figure 19). The basement in this region shows a blocky character, and layer velocities and relative layer thickness are typical for thinned continental crust. Lower crustal velocities are higher than in the neighbouring unthinned continental crust, and slightly elevated densities are necessary to satisfactorily fit the gravity model. A possible explanation for these higher velocities and densities are intrusions into an originally continental crust during initial breakup, as proposed by Weigel et al. 1982 for the Mauritanian margin. These velocities could also correspond to a layer of magmatic underplating from volcanism at rifting. White et al. (2008) show, that in the Hatton Basin area over melt forms intrusion into the lower crustal layer, in the form of dikes and sills, rather than building a separate underplate layer as previously proposed. In our study area we do not find a charactistic double reflection from the top and base of the a separate underplate layer, as is commonly found at volcanic margins for underplate layers (Klingelhoefer et al., 2005). We therefore prefer the interpretation of volcanic intrusions, which would create a smooth increase of velocity without creating a strong reflection.

The crust west of the zone of crustal thinning shows a blocky basement character and relatively high lower crustal velocities $(6.8-7.2 \mathrm{~km} / \mathrm{s})$, which do not 
correspond to oceanic layer 3 or continental lower crustal velocities. It is situated west of the opening anomaly S1 and was therefore created after the initial opening of the ocean. On Profile GH situated in this zone, the underlying crust is about around $8 \mathrm{~km}$ thick and the lower crustal velocity between $6.9-7.3$ $\mathrm{km} / \mathrm{s}$ along the complete profile (Figure $19(\mathrm{~A})$ ). The crustal thickness is 9 $\mathrm{km}$ along the central portion of the profile EF, slightly thicker than on Profile GH and thinning towards the south (Figure 19 (B)). We cannot discern the composition of the crust in this region from our modelling due to the lower quality of S-wave arrivals and its location underneath two low-velocity layers. Different hypothesises for the composition of this crust are (a) Thin oceanic crust formed at very slow spreading rates, with an elevated percentage of serpentinite in the lower crust leading to slightly higher seismic velocities (b) Exhumed upper mantle material from amagmatic spreading at the begining of the opening of the ocean and serpentinised by seawater intruding into the crust through the westward dipping faults (Figure $18 \mathrm{~B}$ ). This type of crust is found on non-volcanic margins such as the Iberian margin (Dean et al., 2000) or the Nova Scotia margin (Funck et al., 2004). In this case the Moho reflection corresponds to the base of the serpentinization front or oceanic crust with high velocity magmatic intrusions or underlying underplate underplate. Bearing in mind location of this domain next to a volcanically underplated or intruded continental crust, we prefer the first hypothesis of oceanic crust by very slow spreading as the full-spreading rate at the opening up to $165 \mathrm{Ma}$ were only about $0.8 \mathrm{~cm} / \mathrm{y}(?)$.

The fourth region is the oceanic crust (0 to $375 \mathrm{~km}$ model distance on Profile Nord) showing a smooth basement and elevated lower crustal velocities (7.00 - $7.40 \mathrm{~km} / \mathrm{s}$ ), located east of M25 magnetic anomaly. The crustal thickness is 
slightly larger (around $8.5 \mathrm{~km}$ ) than west of M25. Possible explanations for the elevated lower crustal velocities and crustal thickness are (a) anomalies of mantle temperature or high spreading rate during the accretion of the crust (b) unusual oceanic crust including a high degree of serpentinite and or other unusual material from the original opening of the ocean. As the full-spreading rate at the time of formation of the crust was about $4.8 \mathrm{~cm} / \mathrm{y}(?)$, which implies that the crust in this area is unusually smooth for a slow spreading centre. Similar smoothness and thickness has been found for Mezozoic crust in the western North Atlantic Minshull (1999). A possible explanation for this type of crust is a small scale mantle temperature anomaly at the time of its formation.

In the fifth region west of M25 magnetic anomaly it is characterized two layers, oceanic layer 2 and 3, of 2.5 and $5.5 \mathrm{~km}$ thickness (Figure $19 \mathrm{D}$ ). Velocities range from $5.5-6.00 \mathrm{~km} / \mathrm{s}$ and $6.60-6.90 \mathrm{~km} / \mathrm{s}$. Layer thickness and velocities are characteristic for oceanic crust (White et al., 1992a). In the reflection seismic section the basement shows typical undulations with a $20 \mathrm{~km}$ wavelength. Oceanic crust found west of M25 magnetic anomaly is characteristic for normal oceanic crust from slow Atlantic-type spreading (White et al., 1992a). At anomaly M25 spreading velocities decreased from $4.8 \mathrm{~cm} / \mathrm{y}$ to $2.6 \mathrm{~cm} / \mathrm{y}(?)$. We propose, that the M25 anomaly marks a major change in spreading velocity which induced a change in the nature of the oceanic crust. A change of spreading velocity has also been proposed as cause for a change from rough to smooth basement characteristics in the Canary island region (Ranero, 1997).

A deep seismic survey has been carried out on the conjugate margin of the United States in the Baltimore Canyon Trough (Diebold et al., 1988) using 
expanding spread and large aperture seismic profiling. Interpretation of the dataset reveals an high velocity "cap" overlying sediments with lower velocities, similar to our dataset. The authors interprete this "cap" as carbonate sequence. They also observe a $7.2 \mathrm{~km} / \mathrm{s}$ velocity layer underneath the carbonate sequence, similar to our lower crustal layer, which appears continuously across the entire Baltimore Canyon Trough from continental to oceanic crust. The authors propose that the rifting process involves the production of this high velocity material. We propose that the origin of this layer is the same than that of the high velocity layer we find from modelling of our dataset.

Deep seismic studies onland Morocco yielded continental crustal thicknesses underneath the Anti-Atlas of $30 \mathrm{~km}$ thinning to approximately $24 \mathrm{~km}$ towards the Atlantic coast at Tiznit (Makris et al., 1985). This and the Moho depth of up to $30 \mathrm{~km}$ found from wide-angle seismic and gravity modelling off Mauritania by Weigel et al. (1982) compare well to the Moho depth of around 27 $\mathrm{km}$ underneath the continental crust found in this study. In the study area of Weigel et al. 1982 north of our study area the zone of transitional crust is about $100 \mathrm{~km}$ wide and interpreted to consist of stretched continental crust intermingled with mafic intrusions in the lower crust. The oceanic crust has a thickness of about $9 \mathrm{~km}$ with anomalous high lower crustal velocities similar to the thickness and velocities found in this study for oceanic crust east of magnetic anomaly M25. Equally no igneous underplating has been found by Weigel et al. (1982).

Continental crustal thickness in northern Morocco was determined to be around $35 \mathrm{~km}$ (Contrucci et al., 2004), which is $7 \mathrm{~km}$ thicker than found for southern Morocco in this study (Figure 20). Both regions show deep sedimentary basins at the foot of the continental slope. Crustal thinning is more asymmet- 
rical in the southern moroccan profiles, where Moho depth decreases west of the incease of basement depth. No oceanic crust with anomalously high lower crustal velocities is found in northern Morocco on the Sismar Profile, but offshore central Morocco a high velocity lower crustal body associated with increased crustal thickness has been modelled from sonobuoy refraction seismic data (Holik et al., 1991), similar to the region of high velocities in oceanic crust found in this study. Holik et al. 1991 interpret the high velocities as underplate from the passage of the Canary Hot Spot, but an alternative explanation might be serpentinite in the lower crust during the onset of seafloor spreading. The zone of continental thinning is about $150 \mathrm{~km}$ wide on the Sismar profiles 4, while less than $100 \mathrm{~km}$ wide on Dakhla Profile Nord 20).

\section{Conclusions}

Modelling of combined wide-angle seismic and reflection seimic data from

4 profiles on the continental margin off the West African Atlantic margin $\left(22^{\circ} \mathrm{N}\right)$ provide images into the deep structure of the margin from unthinned continental crust to the neighbouring oceanic crust.

Five different regions have been distinguished on the basis on these observations:

1) Unthinned continental crust of about $27 \mathrm{~km}$ thickness, composed of two layers of 12 and $15 \mathrm{~km}$ thickness. The crustal thickness is slightly thinner than on the north Moroccan margin.

2) A zone of crustal thinning displaying elevated lower crustal velocities. Their origin could be either magmatic underplating or intrusions into the lower 
crustal layer. As no double reflection which would be characteristic for a separate underplate layer has been found from modelling of the wide angle seismic data, we propose that the high velocities are due to magmatic intrusions in forms of sill and dikes during breakup, as have been imaged by deep reflection seismic data on the volcanic Hatton Bank and Faroe Margin White et al. (1992b).

3) A zone of crust of unknown composition underneath an up to $10 \mathrm{~km}$ thick sedimentary basin. The crust in this region displays velocities anomalous for oceanic crust, but its position east of the breakup anomaly indicates oceanic rather than continental origin. Its basement is characterized by a blocky character. Possible origin of this material could be exhumed serpentinised mantle material or thin oceanic crust containing high amounts of serpentinite from very slow spreading between 195-165 Ma. If a moderate quantity of volcanism is inferred for this margin, the second hypothesis seems preferable.

4) A region of oceanic type crust showing relatively high velocities in the lower crust $(7.00-7.40 \mathrm{~km} / \mathrm{s})$ as compared to normal Atlantic oceanic lower crustal velocities (6.69 +- 0.26 (White et al., 1992a)). This region is located west of magnetic anomaly M25. The crust here is characterized by a smooth basement and a slightly higher than normal thickness. Large faults cross-cutting the complete igneous crust are imaged by the coincident reflection seismic data.

5) West of M25 magnetic anomaly the oceanic crust formed at spreading rates around $2.6 \mathrm{~cm} / \mathrm{y}$ and it is crust characterised by typical rough basement, velocities and crustal thickness characteristic for Atlantic type oceanic crust. The change from high velocity oceanic crust to normal oceanic crust at M25, is probably due to a change in seafloor spreading velocity. 
The West African continental Margin at $22^{\circ} \mathrm{N}$ margin is characterised by thicker continental crust than that of the north $(27 \mathrm{~km}$ instead of $35 \mathrm{~km}$ thickness) and a more narrow zone of crustal thinning (less than $100 \mathrm{~km}$ in the south as compared to $150 \mathrm{~km}$ in the north). Deep seismic data from the conjugate margin show a similar layer of high lower crustal velocities which appears continuously across the entire Baltimore Canyon Trough from continental to oceanic crust.

\section{Acknowledgments}

The authors wish to thank the captain and the crew of the N/O Le Nadir and N/O Le Suroit as well as the OBS teams of Ifremer and the University of Lisbon. Many thanks also to all people involved in the landstation and OBS deployment. This work has been partly funded by Total in the framework of the Ifremer-Total DAKHLA project. We would like to thank two anonymous reviewers for their constructive reviews.

\section{References}

Avedik, F., Renard, V., Allenou, J., Morvan, B., 1993. "Single bubble" air-gun array for deep exploration. Geophysics, 58, 366-382.

Cohen, J. K., Stockwell, J. W., 2003. Seismic Unix Release 37: A free package for seismic research and processing. Center for Wave Phenomena, Colorado School of Mines.

Contrucci, I., Klingelhoefer, F., Perrot, J., Bartolome, R., Gutscher, M.-A., Sahabi, M., Malod, J., Rehault, J.-P., 2004. The crustal structure of the 
NW Moroccan continental margin from wide-angle and reflection seismic data. Geophys. J. Int., 117-128.

Dean, S. M., Minshull, T. A., Whitmarsh, R. B., Louden, K. E., 2000. Deep structure of the ocean-continent transition in the southern Iberia Abyssal Plain from seismic refraction profiles: The IAM-9 transect at $40^{\circ} 20^{\prime} \mathrm{N}$. J. Geophys. Res., 5849-4885.

Diebold, J. B., Stoffa, P. L., the LASE Study Group, 1988. A large aperture seismic experiment in the baltimore canyon trough. in: The Atlantic Continental Margin: U.S., Vol. I-2, The Geological Society of America, 387-398.

Fateh, B., 2003. Détermination des vitesses sismiques dans la région de Dakhla en utilisant des données sismiques. Masters Thesis, Univ. of Rennes, 17.

Funck, T., Jackson, H. R., Louden, K. E., Dehler, S., Wu, Y., 2004. Crustal strucutre of the northern nova scotia continental margin (eastern canada). J. geophys. Res., 109, B009102.

Hinz, K., Dostmann, H., Fritsch, J., 1982. The continental margin of Morocco: seismic sequences, structural elements and geological development. Geology of the Northwest African continental margin, 34-60.

Holik, J. S., Rabinowitz, P. D., Austin, J. A., 1991. Effects of the Canary hotspot volcanism on the structure of oceanic crust off Morocco. J. Geophys. Res., 96, 12039-12067.

Klingelhoefer, F., Edwards, R. A., Hobbs, R. W., England, R. W., 2005. Crustal structure of the NE-Rockall Trough from wide-angle seismic data modelling. J. Geophys. Res., 110, B11105.

Labails, C., Olivet, J.-L., the DAKHLA study group, 2007. Crustal structure of the SW-Moroccan margin from wide-angle and reflection seismic data (the DAKHLA experiment) part b: Tectonic heritage. submitted to: Tectonophysics. 
Ludwig, J. W., Nafe, J. E., Drake, C. L., 1970. Seismic refraction. The Sea, 4, $1,53-84$.

Maillard, A., Malod, J., Thiebot, E., Klingelhoefer, F., Rehault, J.-P., 2006. Imaging a lithospheric detachment at the continent-ocean crustal transition off Morocco. Earth Planet. Sci. Lett., 241 (3-4), 686-698.

Makris, J., Demnati, A., Klussmann, J., 1985. Deep seismic soundings in Morocco and a crust and upper mantle model deduced from seismic and gravity data. Ann. Geophys., 3, 369-380.

McKenzie, D., 1978. Some remarks on the development of sedimentary basins. Earth Planet. Sci. Lett., 40, 25-65.

Minshull, T. A., 1999. On the roughness of Mesozoic oceanic crust in the western North Atlantic. Geophys. J. Int., 286-290.

Ranero, C. R., 1997. The crustal structure of the Canary Basin: accretion processes at slow spreading centers. J. Geophys. Res., 10185-10201.

Roeser, H. A., 1982. Magnetic anomalies in the magnetic quiet zone off Morocco. In: Von Rad, U., Hinz, K. et al. (Eds), Geology of the northwest african continental margin. Springer Verlag, Berlin, Heidelberg, New York, $8,61-68$.

Roeser, H. A., Steiner, C., Schreckenberger, H., Block, M., 2002. Structural development of the Jurassic Magnetic Quiet Zone off Morocco and identification of Middle Jurassic magnetic lineations. J. Geophys. Res., 107, X-1 $\mathrm{X}-23$.

Sahabi, M., 2004. Evolution cinematique triasico-jurassique de l'Atlantique Central : implications sur l'evolution geodynmaique des marges homologues nord ouest africaine et est americaine. These de Doctorat d'Etat Es-Science. Universite Chouaib Doukkali, El Jadida., 615pp.

Sahabi, M., Aslanian, D., Olivet, J.-L., 2004. Un nouveau point de depart pour 
l'histoire de l'Atlantique central. C. R. Geoscience, 336, 1041-1052.

Smith, W., Sandwell, D., 1997. Global seafloor topography from satellite altimetry and ship depth soundings. Science 277, 1956-1962.

Stockwell, J. W., 1999. The CWP/SU: Seismic Un*x Package. Computers and Geosciences 25; 4, 415-419.

Weigel, W., Wissman, G., Goldflam, P., 1982. Deep seismic structure (Mauritania and central Morocco). In: Von Rad, U., Hinz, K. et al. (Eds), Geology of the northwest African continental margin. Springer Verlag, Berlin, Heidelberg, New York, 8, 132-159.

Wernicke, B., 1985. Uniform-sense normal simple shear of the continental lithosphere. Can. J. Earth Sci. 22, 108-125.

White, R. S., McKenzie, D., O’Nions, R., 1992a. Oceanic crustal thickness from seismic measurements and rare earth element inversions. J. Geophys. Res. 97, 19,683-19,715.

White, R. S., Smith, L. K., Roberts, A. W., Christie, P. A. F., Kuznir, N. K., the iSimm Team, 1992b. Oceanic crustal thickness from seismic measurements and rare earth element inversions. J. Geophys. Res. 97, 19,683-19,715.

Whitmarsh, R. B., Manatshall, G., Minshull, T. A., 2008. Lowercrustal intrusion on the North Atlantic continental margin. Nature 452, doi:10.1038/nature06687.

Zelt, C. A., 1999. Modelling strategies and model assessment for wide-angle seismic traveltime data. Geophys. J. Int. 139, 183-204.

Zelt, C. A., Smith, R. B., 1992. Seismic travel time inversion for 2-d crustal velocity structure. Geophys. J. Int. 108, 16-31. 


\section{Figure captions}

Figure 1: (A) Location of the study area off the southern Moroccan continental margin marked by black outlined rectangle. Isocontours are predicted bathymetry from satellite altimetry (Smith and Sandwell, 1997) contoured every $2500 \mathrm{~m}$. Green lines mark Profiles from the Sismar deep seismic cruise Contrucci et al. (2004), blue line Profile VAL75II, VAL75III and VAL75IV Weigel et al. (1982) and red line the North Tarfaya Profile Hinz et al. (1982). (B) Magnetic anomaly of the study area (Roeser et al., 2002) and location of the seismic profiles (black lines). Ocean bottom instrument locations are marked by circles and landstation location by inverted triangles. Thin black line marks multichannel seismic profiles shot by the "Grosse Bertha" airgun array and dashed black line reflection seismic profiles shot by the "Bulle" airgun array. Grey dashed line shows location of the S1 magnetic anomaly, small dashed line location of the hinge line and large dashed line location of the M25 magnetic anomaly (?). Main geographic features are annontated. Frame shows location of Figure 1C. (C) Multibeam bathymetry of the study area from side scan sonar data. Ocean bottom instrument locations are marked by circles and thin black line marks multichannel seismic profiles shot by the "Grosse Bertha" airgun array.

Figure 2: (a) Bandpass filtered (3-5 Hz, 24-36 Hz) data from OBS N76 on Profile Nord. The data are gain-adjusted according to offset and reduced to a velocity of $6 \mathrm{~km} / \mathrm{s}$. (b) Synthetic seismograms calculated from the model for the same station using the finite-difference modelling code from the Seismic Unix package (Cohen and Stockwell, 2003; Stockwell, 1999). The synthetic seismograms are calculated every $100 \mathrm{~m}$ with a source frequency centred around 5 
$\mathrm{Hz}$.

Figure 3: (a) Data from OBS N53 on Profile Nord with the same gain, filter and scaling applied as in Figure 2. (b) Corresponding synthetic seismograms.

Figure 4: (a) (a) Data from OBS N44 and N44a on Profile Nord with the same gain, filter and scaling applied as in Figure 2. (b) Corresponding synthetic seismograms.

Figure 5: (a) Data from landstation DK03 on Profile Nord with the same gain, filter and scaling applied as in Figure 2. (b) Corresponding synthetic seismograms.

Figure 6: (a) Data from OBS S11 on Profile Sud with the same gain, filter and scaling applied as in Figure 2. (b) Corresponding synthetic seismograms.

Figure 7: (a) Data from OBS N53 on Profile GH with the same gain, filter and scaling applied as in Figure 2. (b) Corresponding synthetic seismograms.

Figure 8: (a) Data from OBS N51 on Profile EF with the same gain, filter and scaling applied as in Figure 2. (b) Corresponding synthetic seismograms.

Figure 16: Reflection seismic sections for the all four Profiles. Model boundaries from wide-angle modelling converted to two-way travel-time are overlain. OBS locations are indicated by red circles and landstations by red inverted triangles. (A) Profile GH (B) Profile EF (C) Profile N (D) Profile S. Frames show position of blow-ups of Figure 18.

Figure 9: Final velocity models for the all four Profiles including the model boundaries used during inversion (solid lines) and isovelocity contours every $0.20 \mathrm{~km} / \mathrm{s}$. OBS locations are indicated by red circles and landstation locations 
by red inverted triangles. Areas unconstrained by raytracing modelling are shaded. Vertical ex. 1:5. (A) Profile GH (B) Profile EF (C) Profile N (D) Profile S.

Figure 10: (a) Upper panel: Ray coverage of the sedimentary layers of Profile Nord with every tenth ray from two-point ray-tracing plotted. Lower panel: Observed traveltime picks and calculated travel times (line) of the sedimentary layers for all receivers along the model. (b) Same as (a) but for the crustal layers (c) Same as (a) but for the Moho and upper mantle layers.

Figure 11: (a) Upper panel: Ray coverage of the sedimentary layers of Profile Sud with every tenth ray from two-point ray-tracing plotted. Lower panel: Observed traveltime picks and calculated travel times (line) of the sedimentary layers for all receivers along the model. (b) Same as (a) but for the crustal layers (c) Same as (a) but for the Moho and upper mantle layers.

Figure 12: (a) Upper panel: Ray coverage of the sedimentary layers of Profile GH with every tenth ray from two-point ray-tracing plotted. Lower panel: Observed traveltime picks and calculated travel times (line) of the sedimentary layers for all receivers along the model. (b) Same as (a) but for the crustal layers (c) Same as (a) but for the Moho and upper mantle layers.

Figure 13: (a) Upper panel: Ray coverage of the sedimentary layers of Profile EF with every tenth ray from two-point ray-tracing plotted. Lower panel: Observed traveltime picks and calculated travel times (line) of the sedimentary layers for all receivers along the model. (b) Same as (a) but for the crustal layers (c) Same as (a) but for the Moho and upper mantle layers.

Figure 14: Resolution parameter for all velocity nodes of the final velocity 
models. White and yellow arreas can be considered well resolved. OBS positions are indicated by red circles and landstations by red inverted triangles.

Figure 15: Results from gravity modelling. Positions of OBSs (circles) and landstations (inverted triangles) are indicated. Italic numbers give densities used for gravity modelling in $\mathrm{g} / \mathrm{cm}^{3}$. Black line indicate layer boundaries from seismic modelling. Numbers in brackets give initial density where different from final density. (A) Upper panel: Shipboard measured free-air gravity anomaly (black line), predicted anomaly from initial model (dotted line) and from final model (dashed line) along Profile GH. Lower panel: Gravity model of Profile GH. (B) Upper panel: Shipboard measured free-air gravity anomaly (black line) and predicted anomaly from initial model (dotted line) and from final model (dashed line) along Profile EF. (C) Upper panel: Shipboard measured free-air gravity anomaly (black line), predicted anomaly from initial model (dotted line) and from final model (dashed line) along Profile Sud. Lower panel: Gravity model of Profile Sud. (D) Upper panel: Shipboard measured free-air gravity anomaly (black line), predicted anomaly from initial model (dotted line) and from final model (dashed line) along Profile Nord.

Figure 17: Nature of the basement along Profile Nord from reflection seismic data. For location of the three blow-ups see Figure 17. OBS positions are marked by red circles, blue lines mark basement reflector, yellow lines intrecrustal reflectors and red lines Moho. (A) Model distance 50 - 100 km, normal oceanic crust characterized by rough basement (B) Model distance 200 - 250 $\mathrm{km}$, oceanic crust characterized by smooth basement, high velocity lower crust and prominent crustal faults (C) Model distance 400 - $450 \mathrm{~km}$, transitional crust. 
Figure 18: Geological cross sections based on the velocity models of (A) Profile GH (B) Profile EF (C) Profile Sud (D) Profile Nord.

Figure 19: (A) Position map of the Sismar and Dakhla wide-angle seismic profiles. S1 magnetic anomaly is marked in red (B) Sismar Profile 4 final velocity model including the model boundaries used during inversion (solid lines) and isovelocity contours every $0.20 \mathrm{~km} / \mathrm{s}$. OBS locations are indicated by red circles and landstation locations by red inverted triangles. Areas unconstrained by raytracing modelling are shaded. Vertical ex. 1:5. (C) Dakhla Profile Nord final velocity model including the model boundaries used during inversion (solid lines) and isovelocity contours every $0.20 \mathrm{~km} / \mathrm{s}$. OBS locations are indicated by red circles and landstation locations by red inverted triangles. Areas unconstrained by raytracing modelling are shaded (Figure 20). 


\section{Tables}

\begin{tabular}{rccccc}
\hline Phase & & No of picks & Mean S/N-ratio & RMS traveltime residual & chi-squared \\
\hline \hline Water & 1 & 2373 & 230.536 & 0.019 & 0.036 \\
Sediments 1 & 2 & 114 & 32.0966 & 0.079 & 0.636 \\
Sediments 3 & 9 & 1151 & 7.9774 & 0.174 & 3.044 \\
Sediments 1 reflection & 4 & 843 & 1.16808 & 0.090 & 0.815 \\
Sediments 2 reflection & 5 & 306 & 1.70894 & 0.109 & 1.199 \\
Sediments 3 reflection & 10 & 555 & 2.42879 & 0.105 & 1.098 \\
Basement & 6 & 246 & 13.6307 & 0.089 & 0.798 \\
Lower crust & 11 & 9513 & 3.33679 & 0.123 & 1.392 \\
Crustal reflection & 12 & 212 & 3.25943 & 0.266 & 7.113 \\
PmP & 7 & 5652 & 1.5279 & 0.151 & 2.077 \\
Pn & 8 & 1174 & 1.4477 & 0.129 & 1.541 \\
\hline All Phases & 23703 & & 0.126 & 1.497
\end{tabular}

Table 1

Traveltime residuals and chi squared error for all phases and the complete model of Profile Nord.

\begin{tabular}{rccccc}
\hline Phase & & No of picks & Mean S/N-ratio & RMS traveltime residual & chi-squared \\
\hline \hline Water & 1 & 512 & 230.536 & 0.024 & 0.827 \\
Sediments 1 & 2 & 48 & 32.0966 & 0.034 & 1.830 \\
Sediments 3 & 9 & 138 & 7.9774 & 0.113 & 20.597 \\
Sediments 1 reflection & 4 & 822 & 1.16808 & 0.045 & 0.753 \\
Sediments 3 reflection & 10 & 731 & 2.42879 & 0.051 & 0.408 \\
Basement & 6 & 821 & 13.6307 & 0.180 & 15.886 \\
Lower crust & 11 & 3588 & 3.33679 & 0.141 & 5.449 \\
PmP & 7 & 2550 & 1.5279 & 0.125 & 3.187 \\
Pn & 8 & 973 & 1.4477 & 0.169 & 2.616 \\
\hline All Phases & 10918 & 0.128 & 4.830 &
\end{tabular}

Table 2

Traveltime residuals and chi squared error for all phases and the complete model of Profile Sud. 


\begin{tabular}{rccccc}
\hline Phase & & No of picks & Mean S/N-ratio & RMS traveltime residual & chi-squared \\
\hline \hline Water & 1 & 864 & 230.536 & 0.015 & 0.562 \\
Sediments 1 & 2 & 17 & 32.0966 & 0.119 & 12.304 \\
Sediments 1 reflection & 4 & 412 & 1.16808 & 0.046 & 0.796 \\
Sediments 3 reflection & 10 & 583 & 2.42879 & 0.125 & 2.222 \\
Basement & 6 & 129 & 13.6307 & 0.123 & 6.085 \\
Lower crust & 11 & 969 & 3.33679 & 0.058 & 0.280 \\
Crustal reflection & 12 & 120 & 3.25943 & 0.057 & 0.476 \\
PmP & 7 & 470 & 1.5279 & 0.076 & 0.395 \\
Pn & 8 & 264 & 1.4477 & 0.103 & 0.683 \\
\hline All Phases & 4718 & 0.074 & 0.986 &
\end{tabular}

Table 3

Traveltime residuals and chi squared error for all phases and the complete model of Profile GH.

\begin{tabular}{rccccc}
\hline Phase & & No of picks & Mean S/N-ratio & RMS traveltime residual & chi-squared \\
\hline \hline Water & 1 & 1115 & 230.536 & 0.020 & 0.935 \\
Sediments 1 reflection & 4 & 338 & 1.16808 & 0.079 & 1.122 \\
Sediments 3 reflection & 10 & 683 & 2.42879 & 0.188 & 2.265 \\
Basement & 6 & 115 & 13.6307 & 0.228 & 3.351 \\
Lower crust & 11 & 2647 & 3.33679 & 0.071 & 0.321 \\
PmP & 7 & 1032 & 1.5279 & 0.088 & 0.513 \\
\hline All Phases & 7994 & 0.106 & 1.038 &
\end{tabular}

Table 4

Traveltime residuals and chi squared error for all phases and the complete model of Profile EF. 


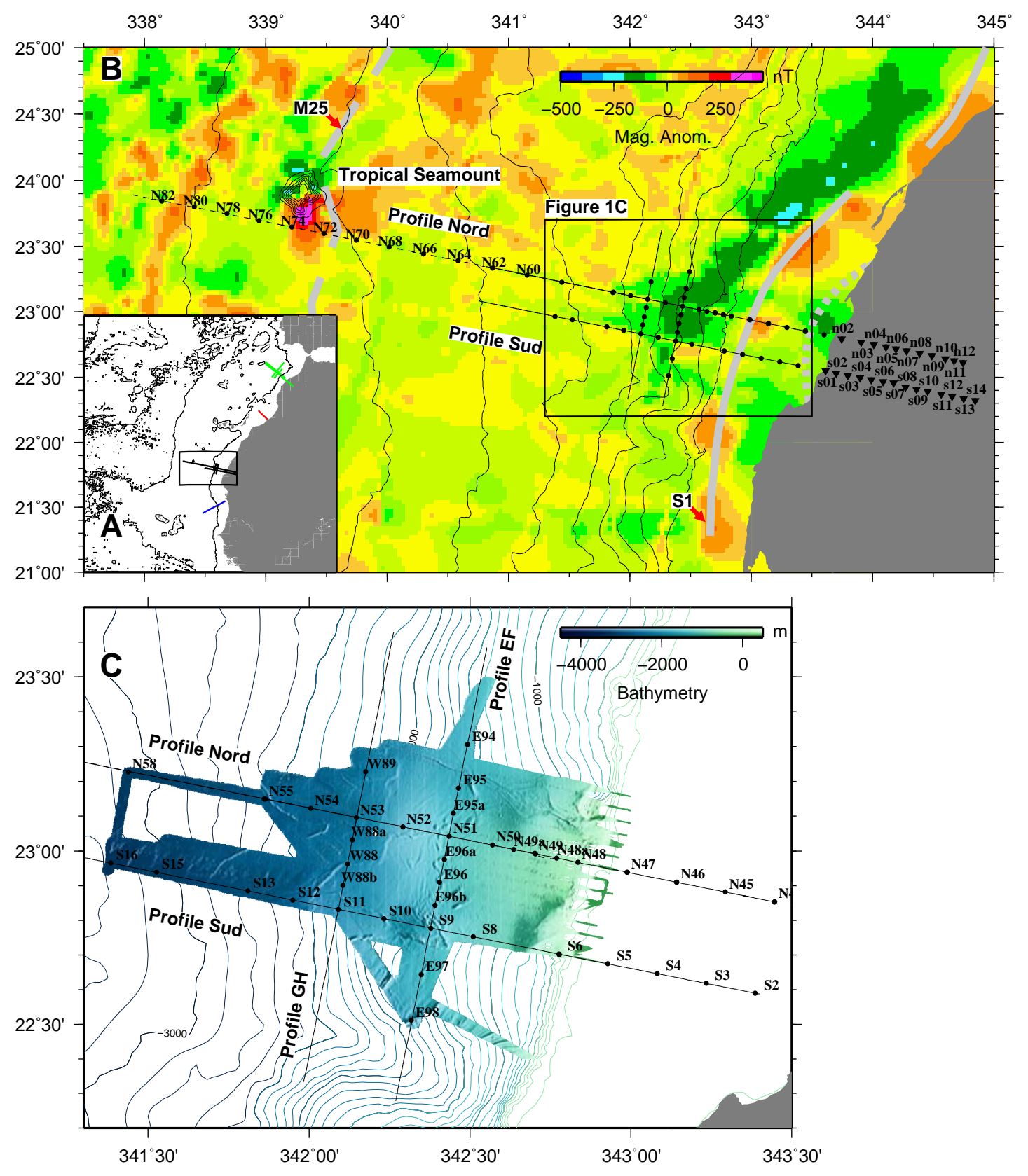

Fig. 1. 


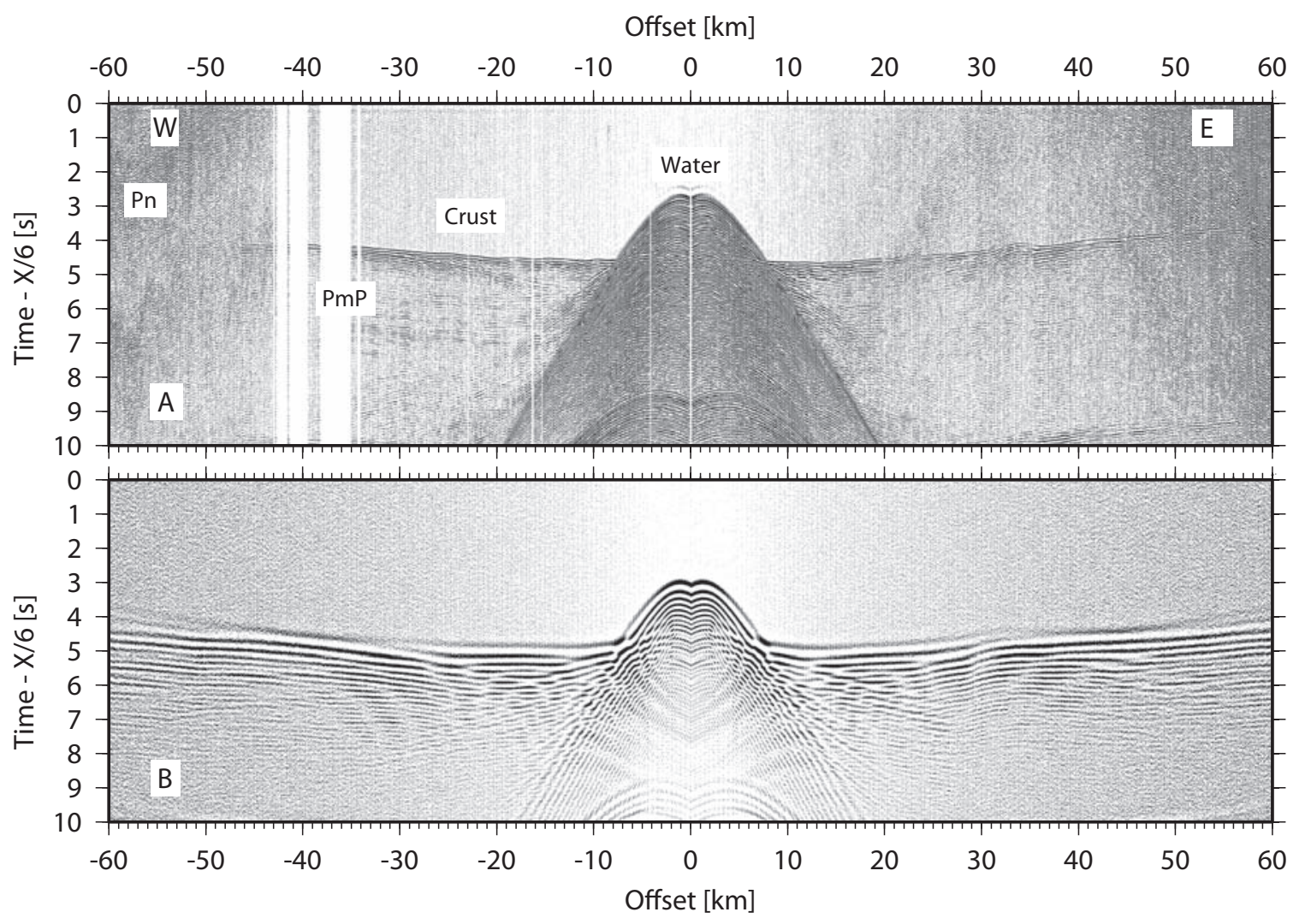

Fig. 2. 


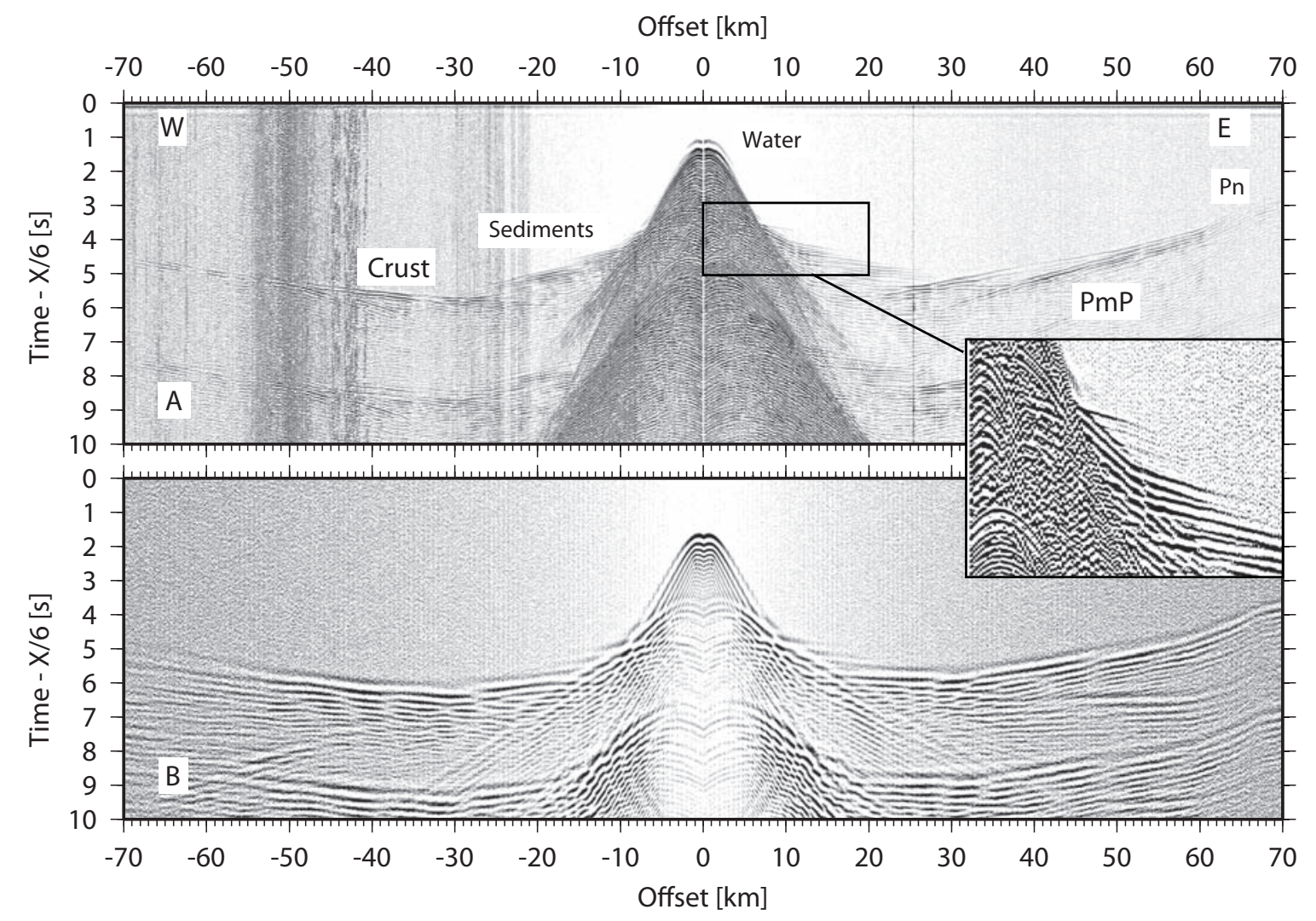

Fig. 3 . 


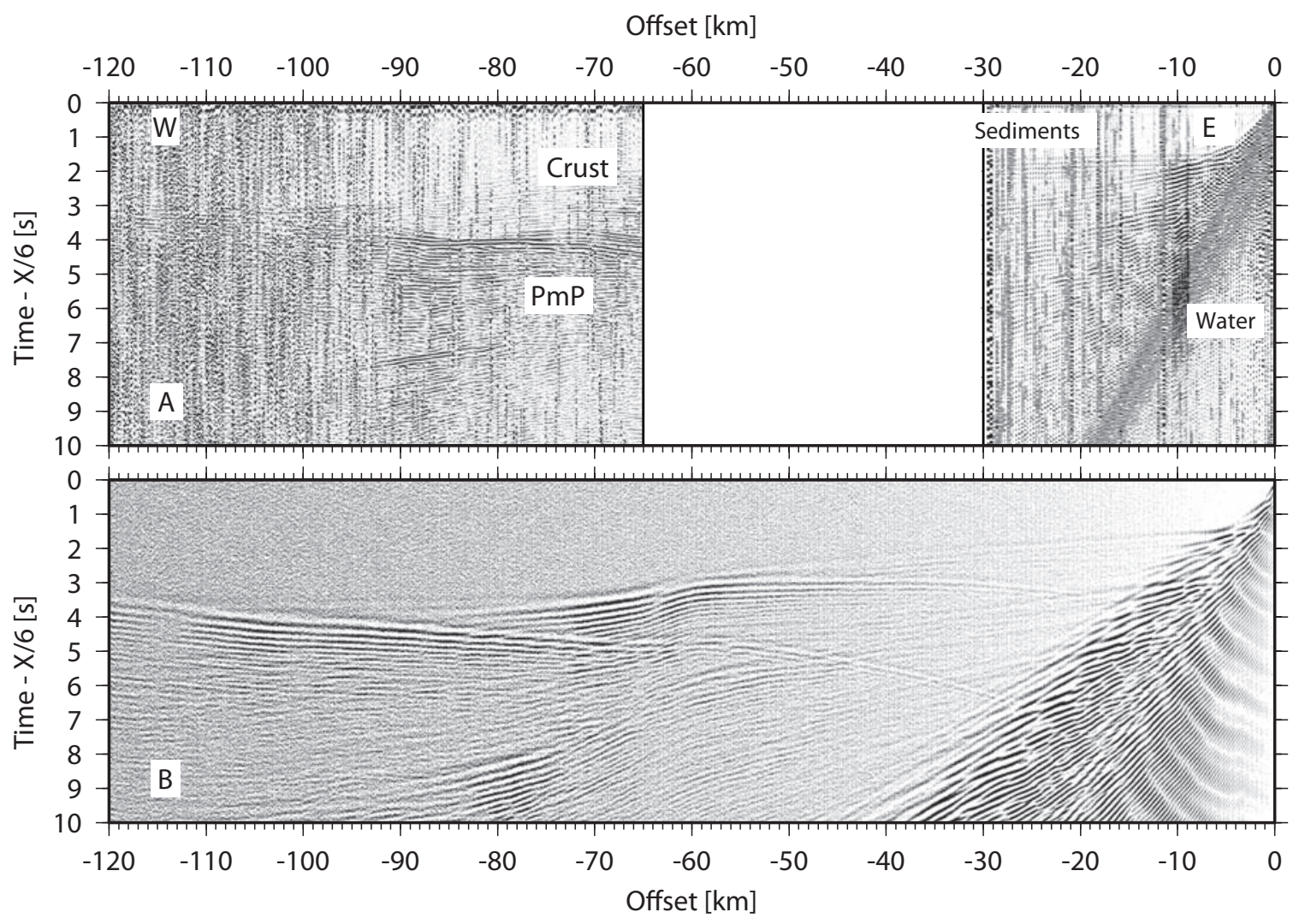

Fig. 4. 


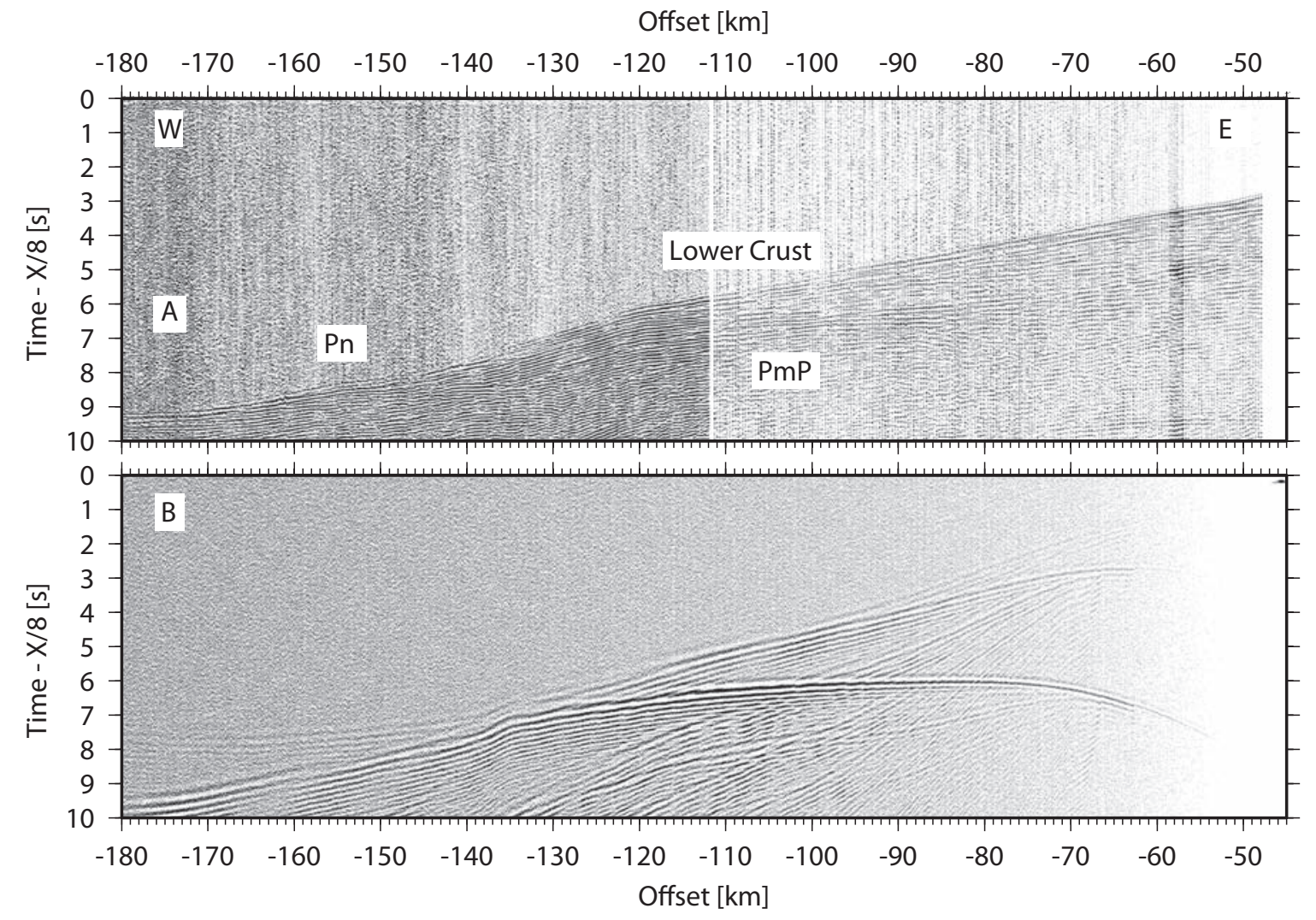

Fig. 5 . 


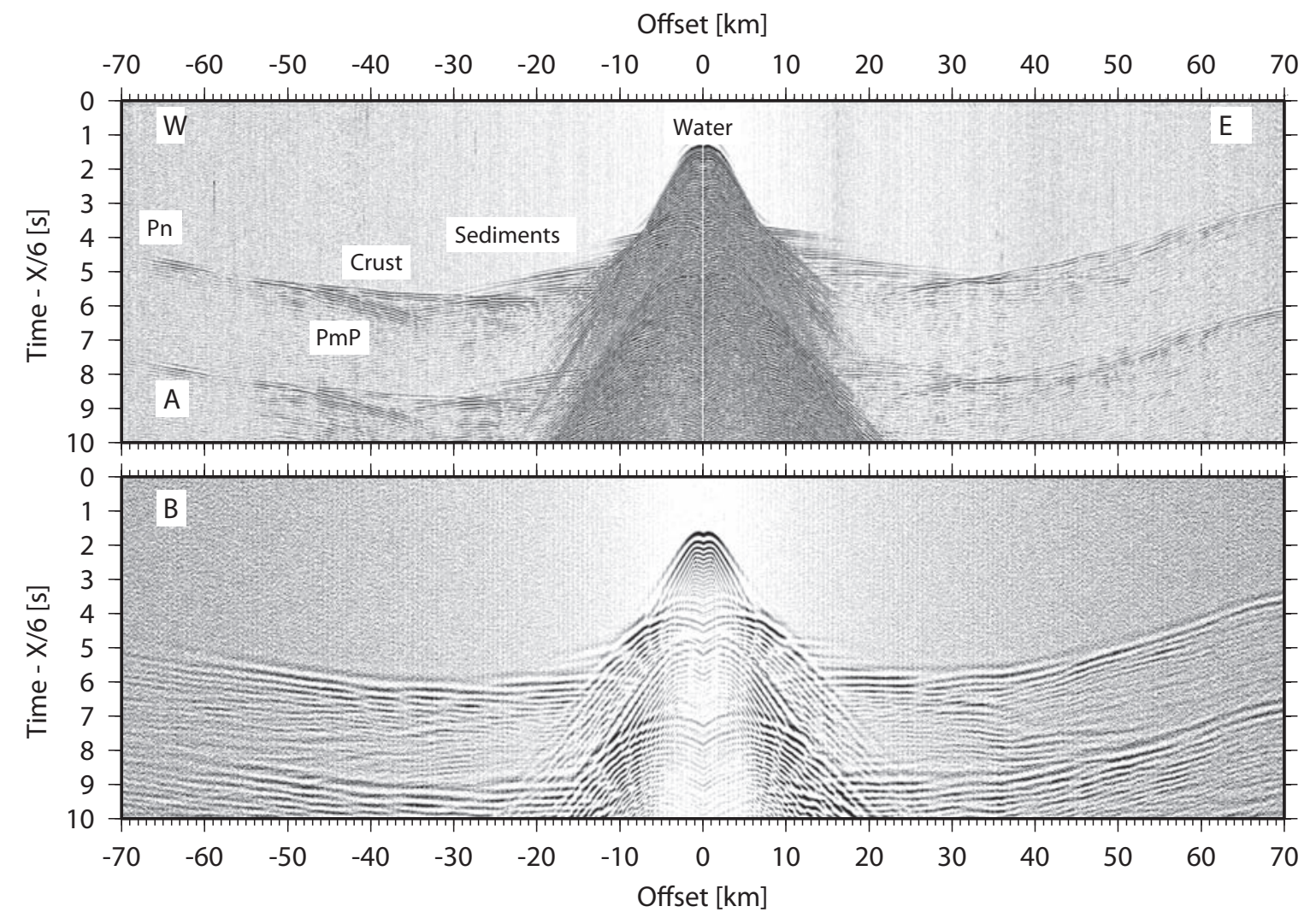

Fig. 6 . 


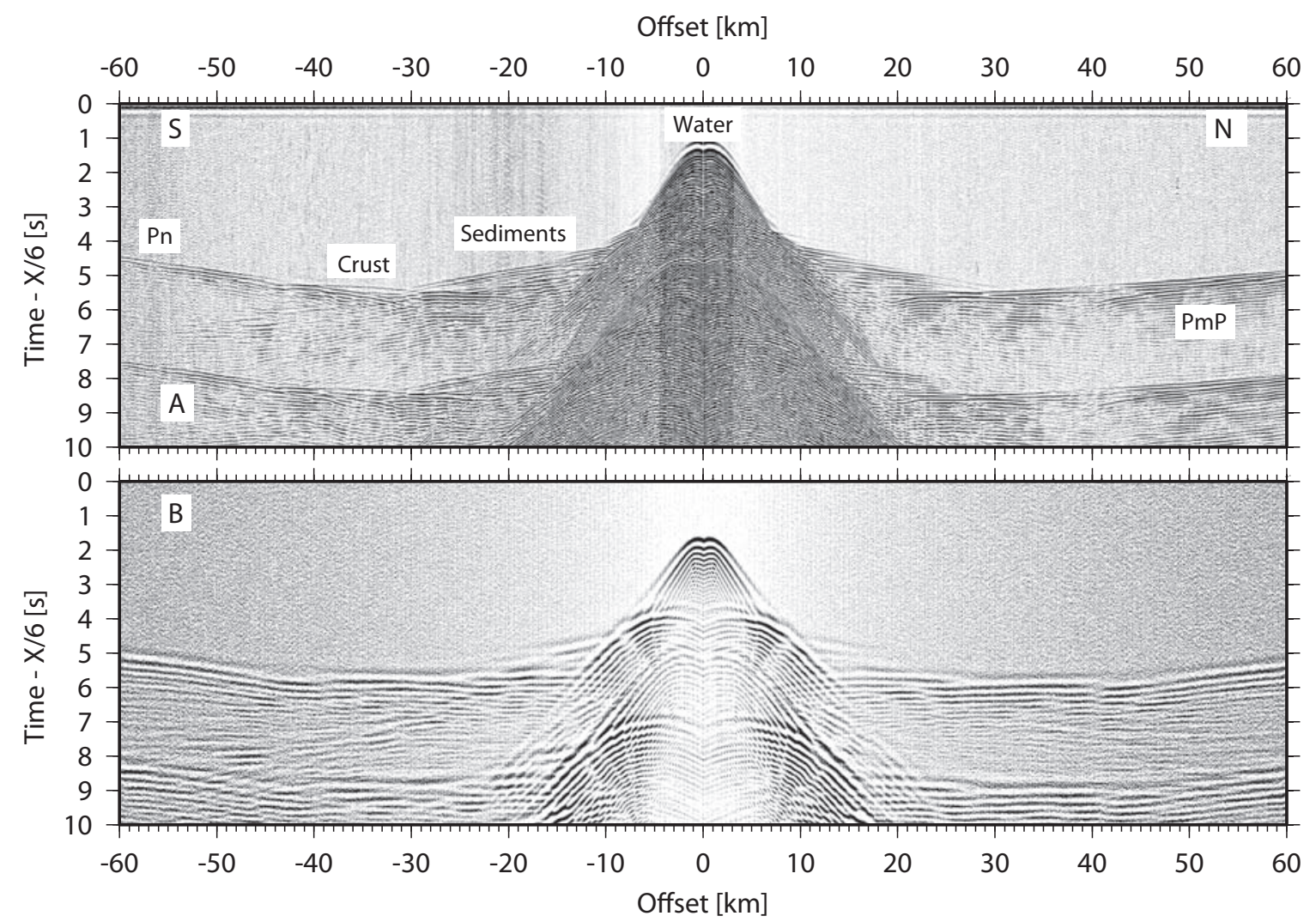

Fig. 7. 


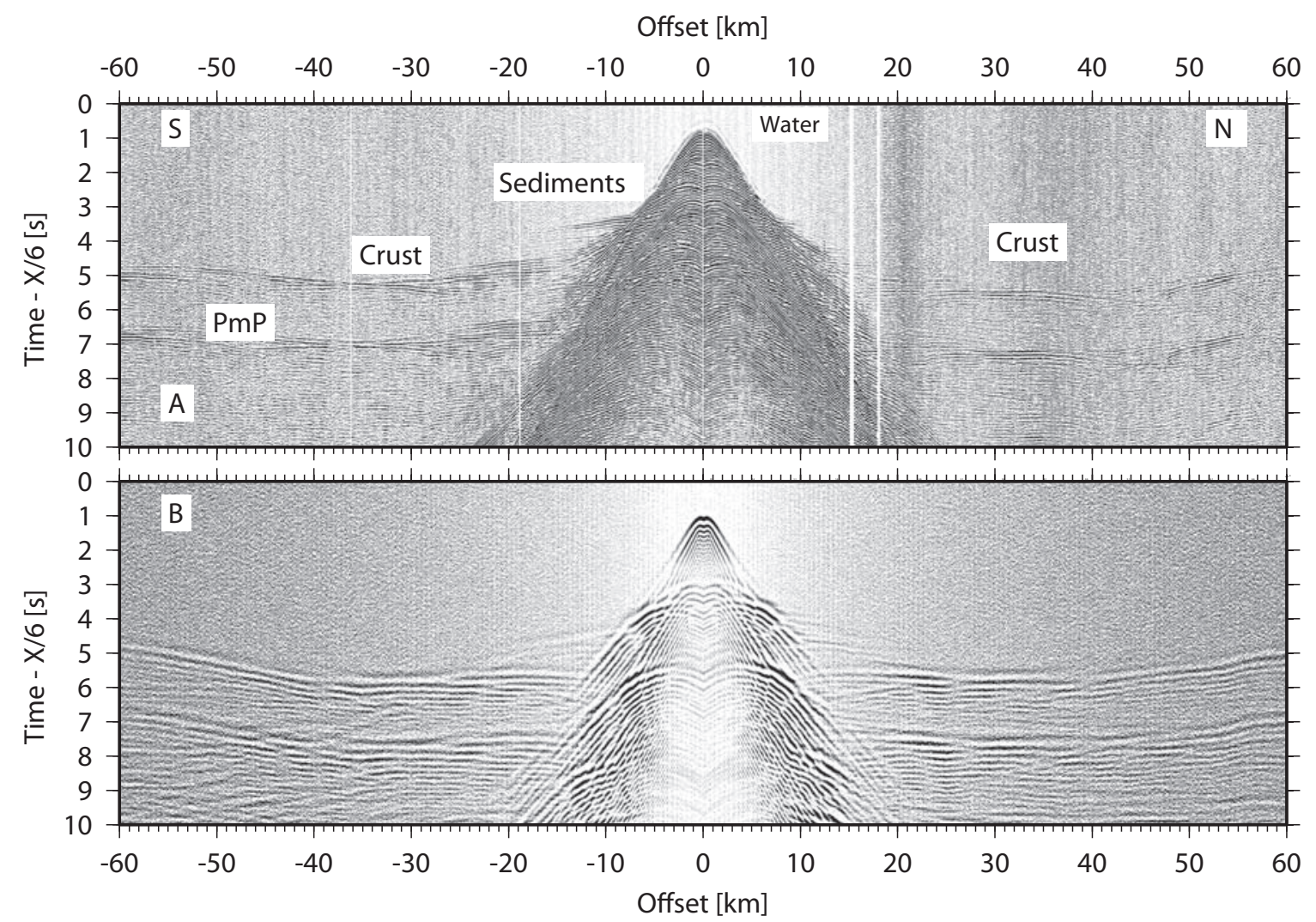

Fig. 8. 

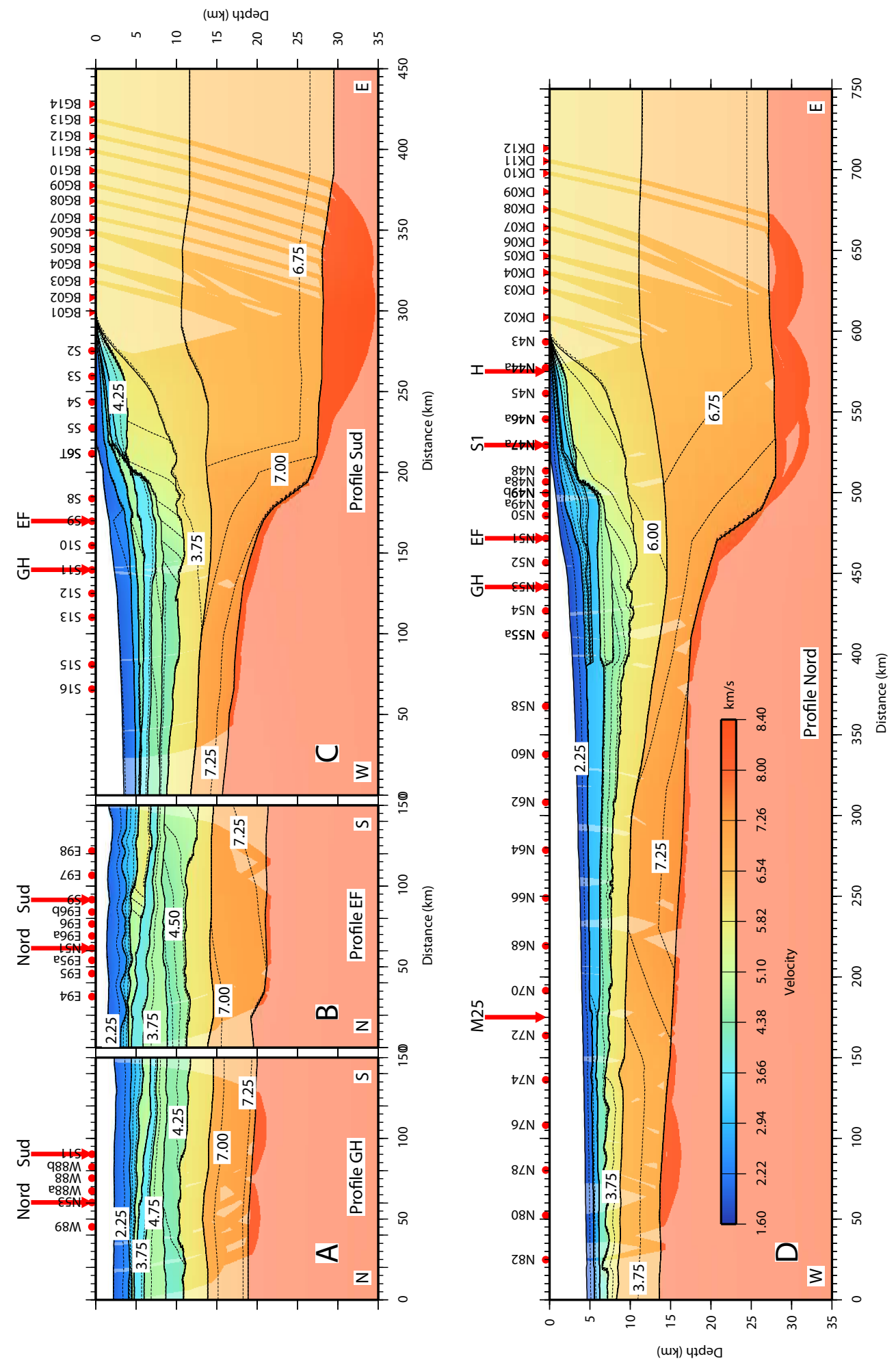

Fig. 9. 


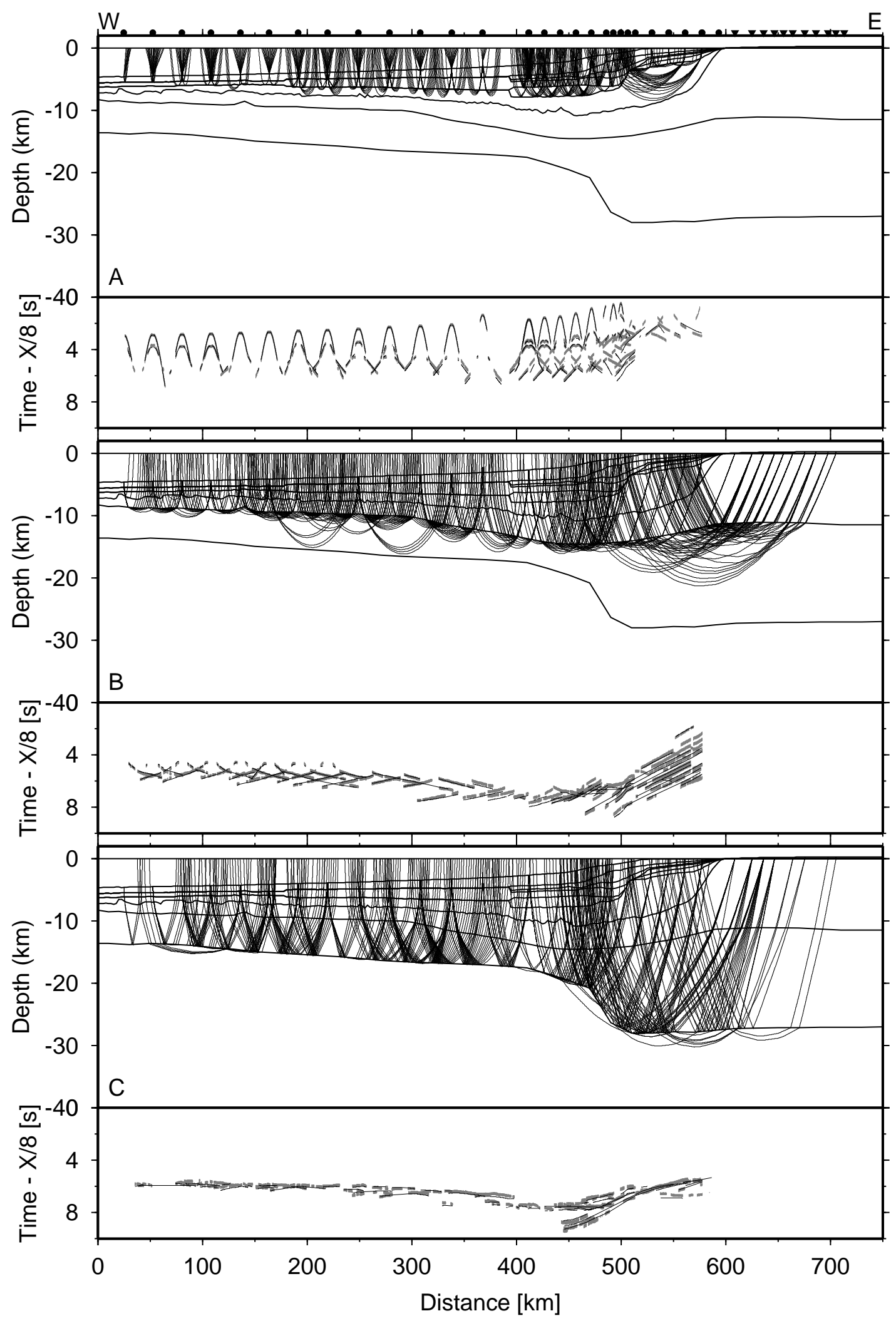

Fig. 10. 


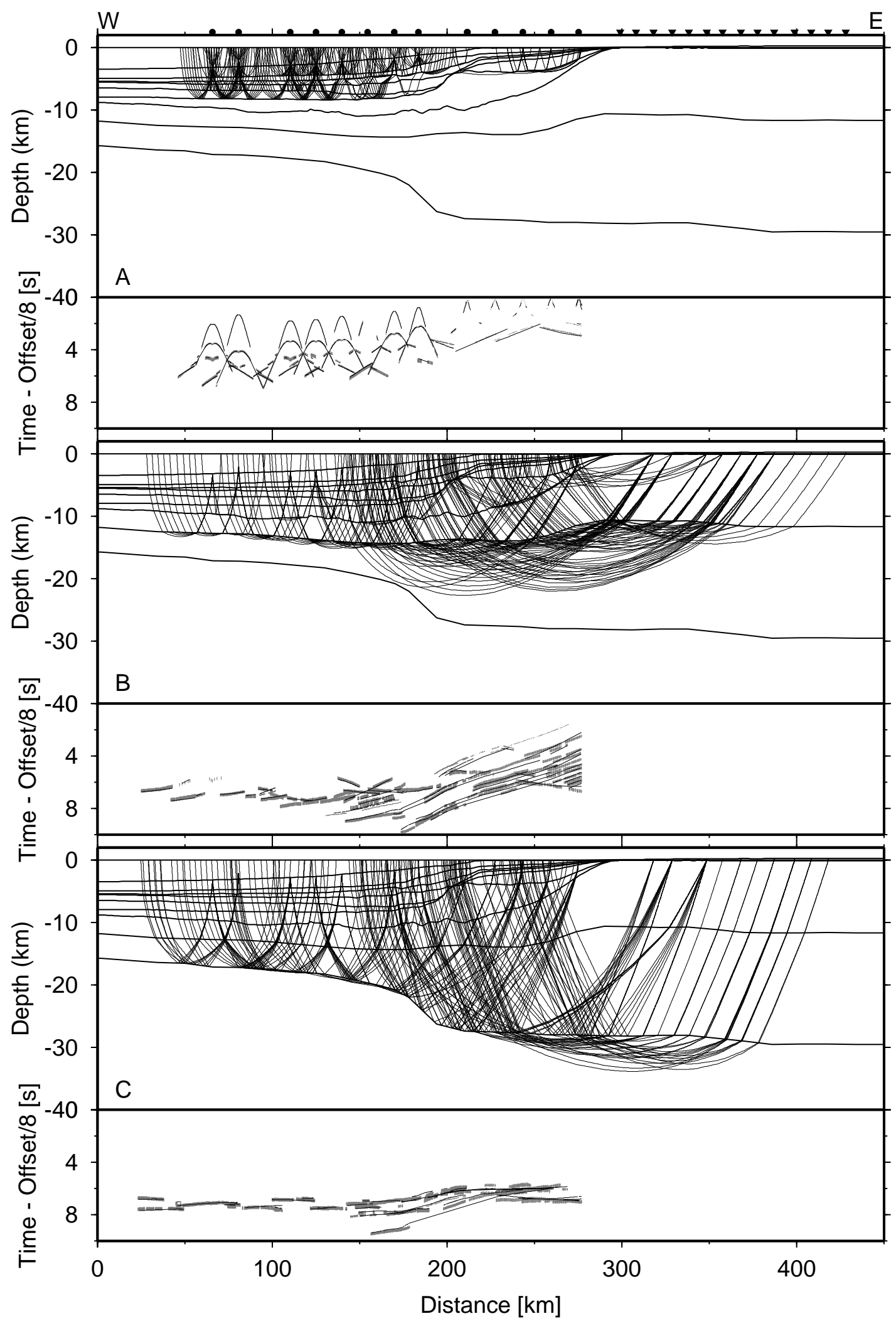

Fig. 11. 


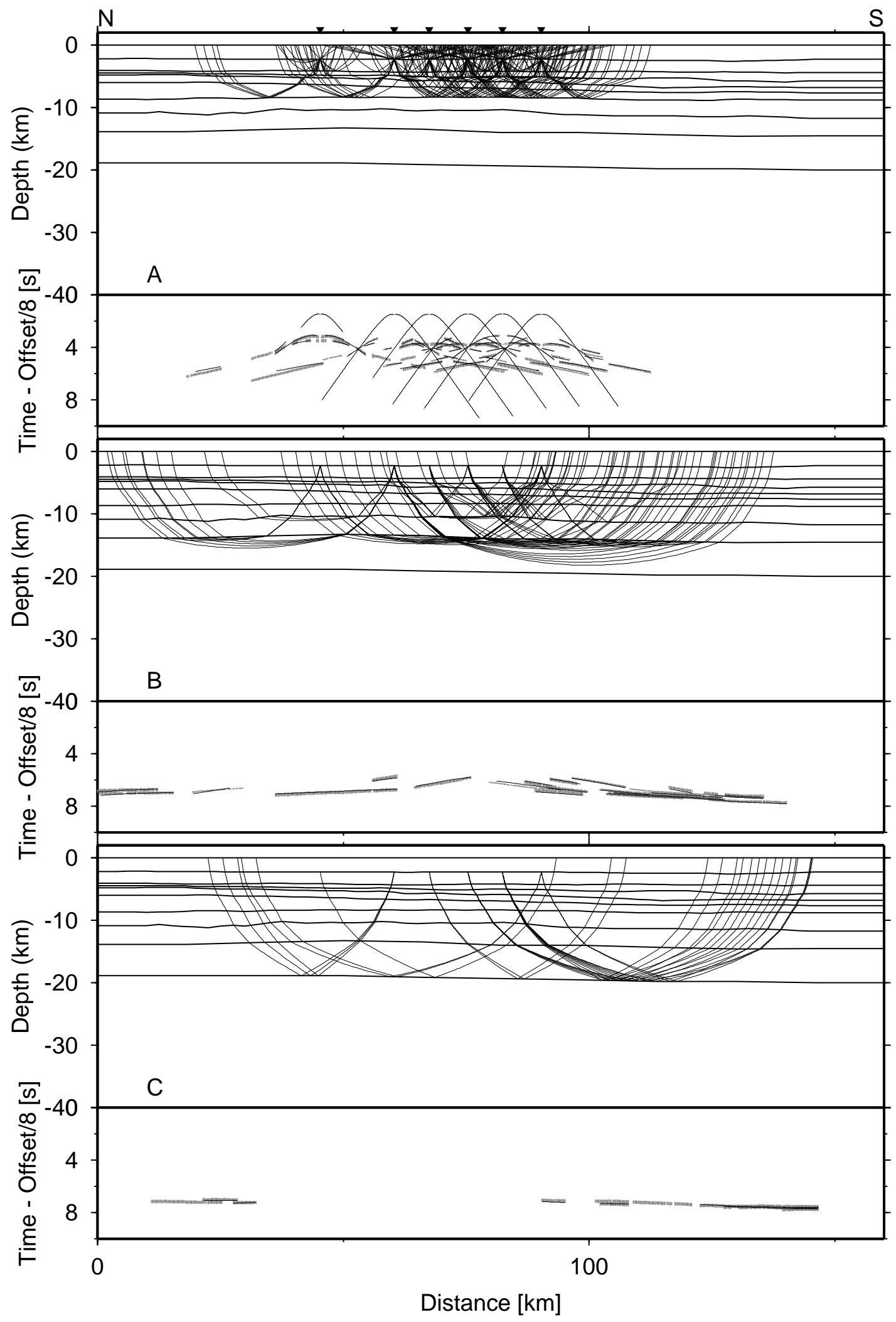

Fig. 12. 


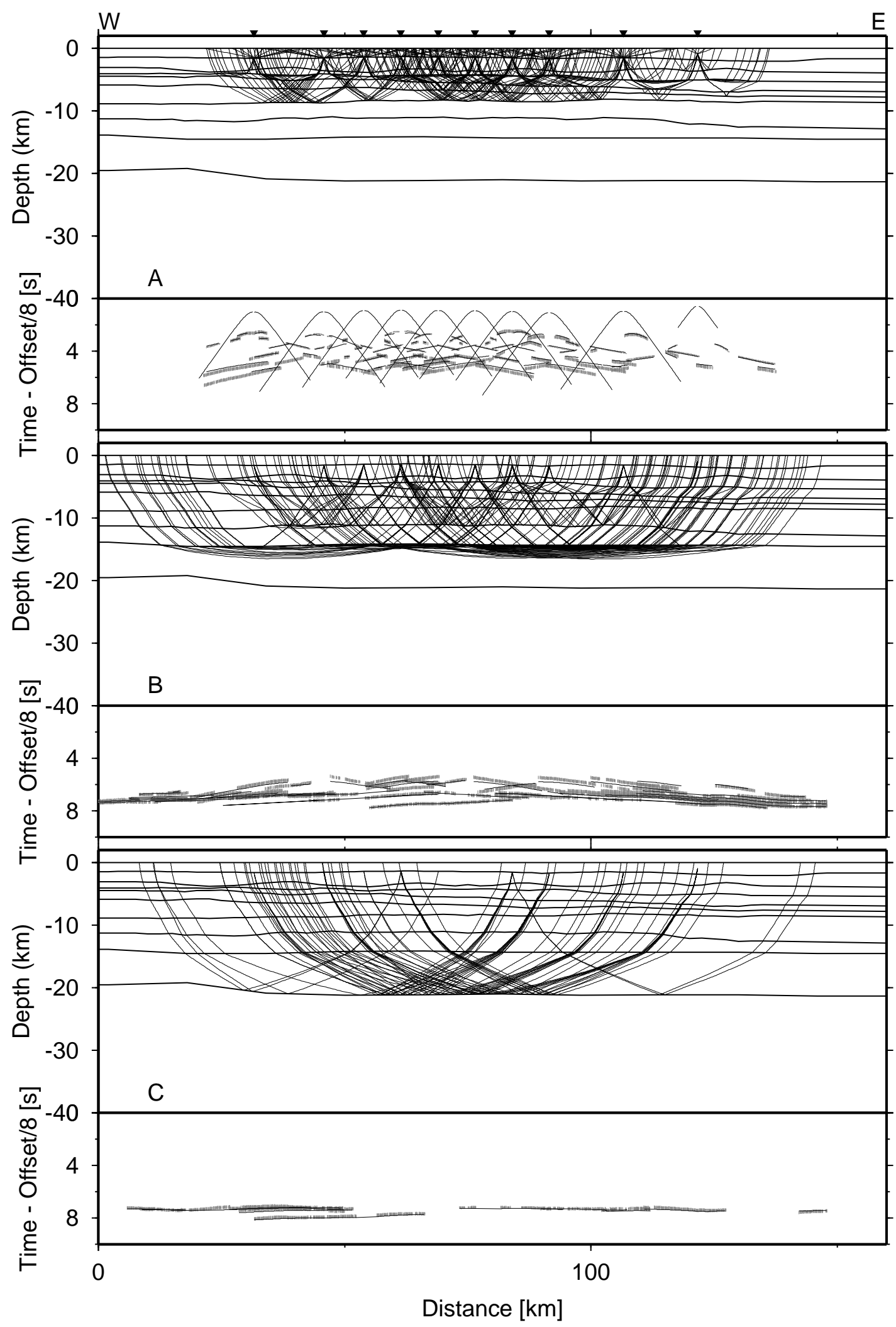

Fig. 13. 

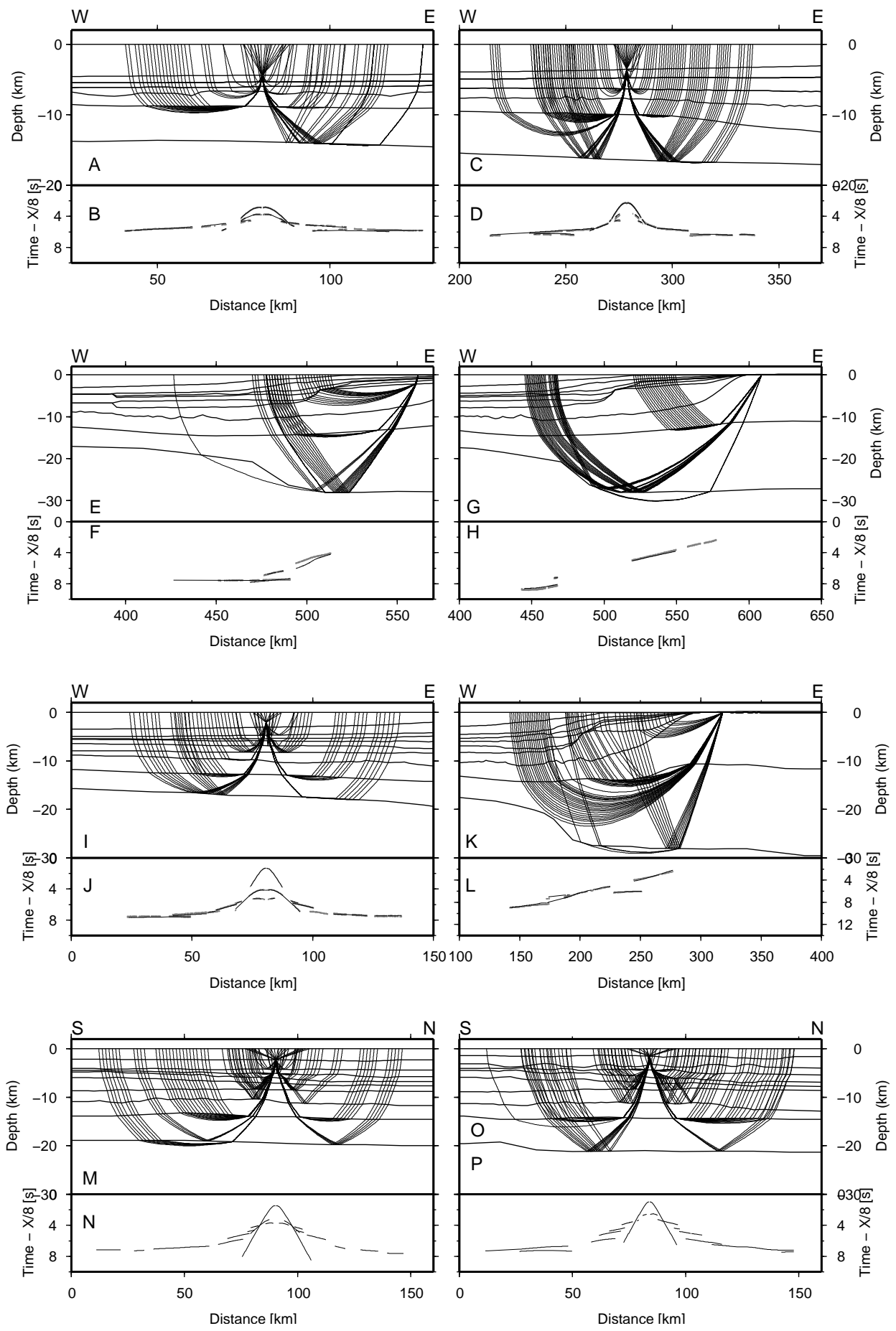

Fig. 14. 

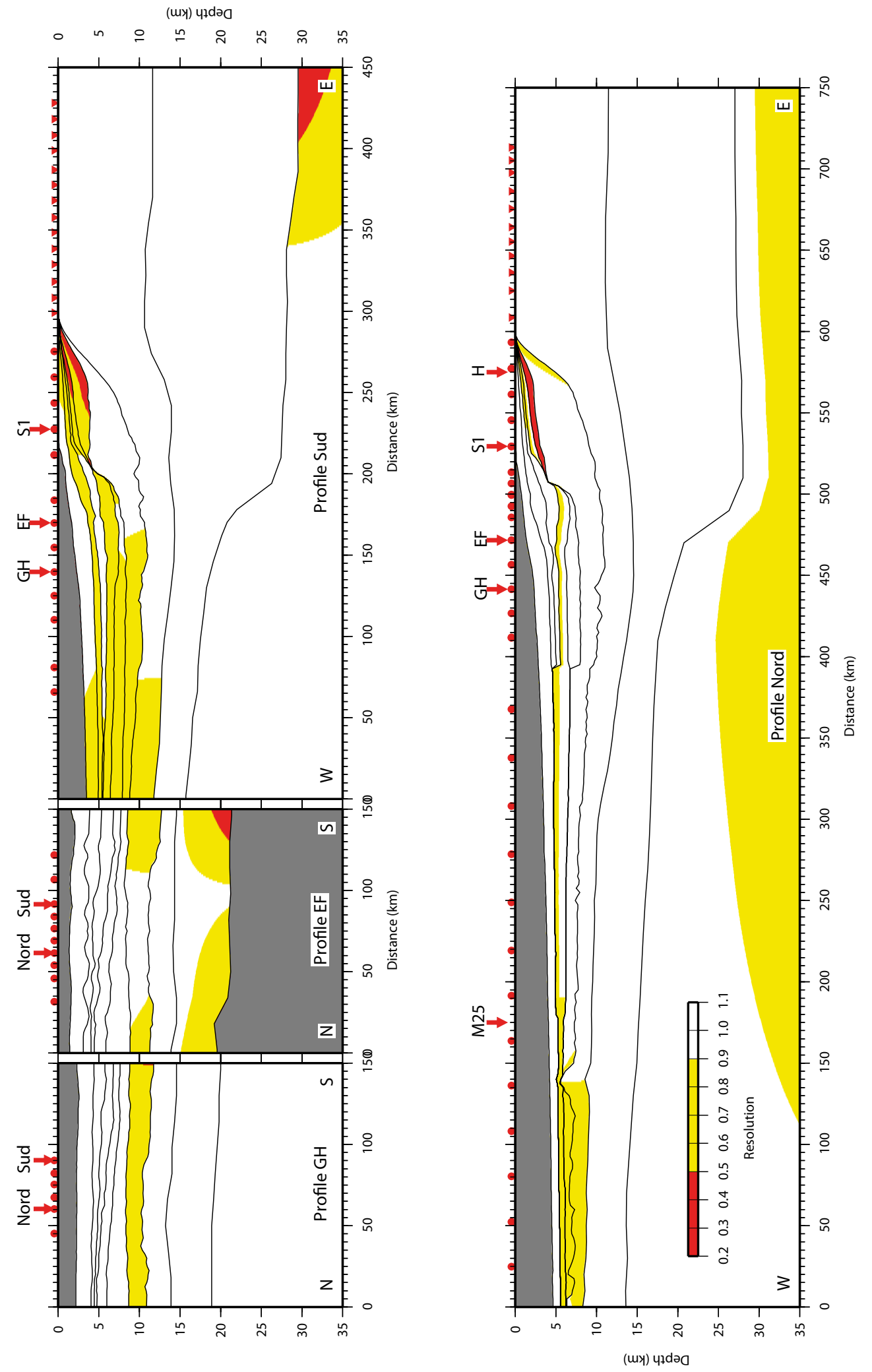

Fig. 15. 

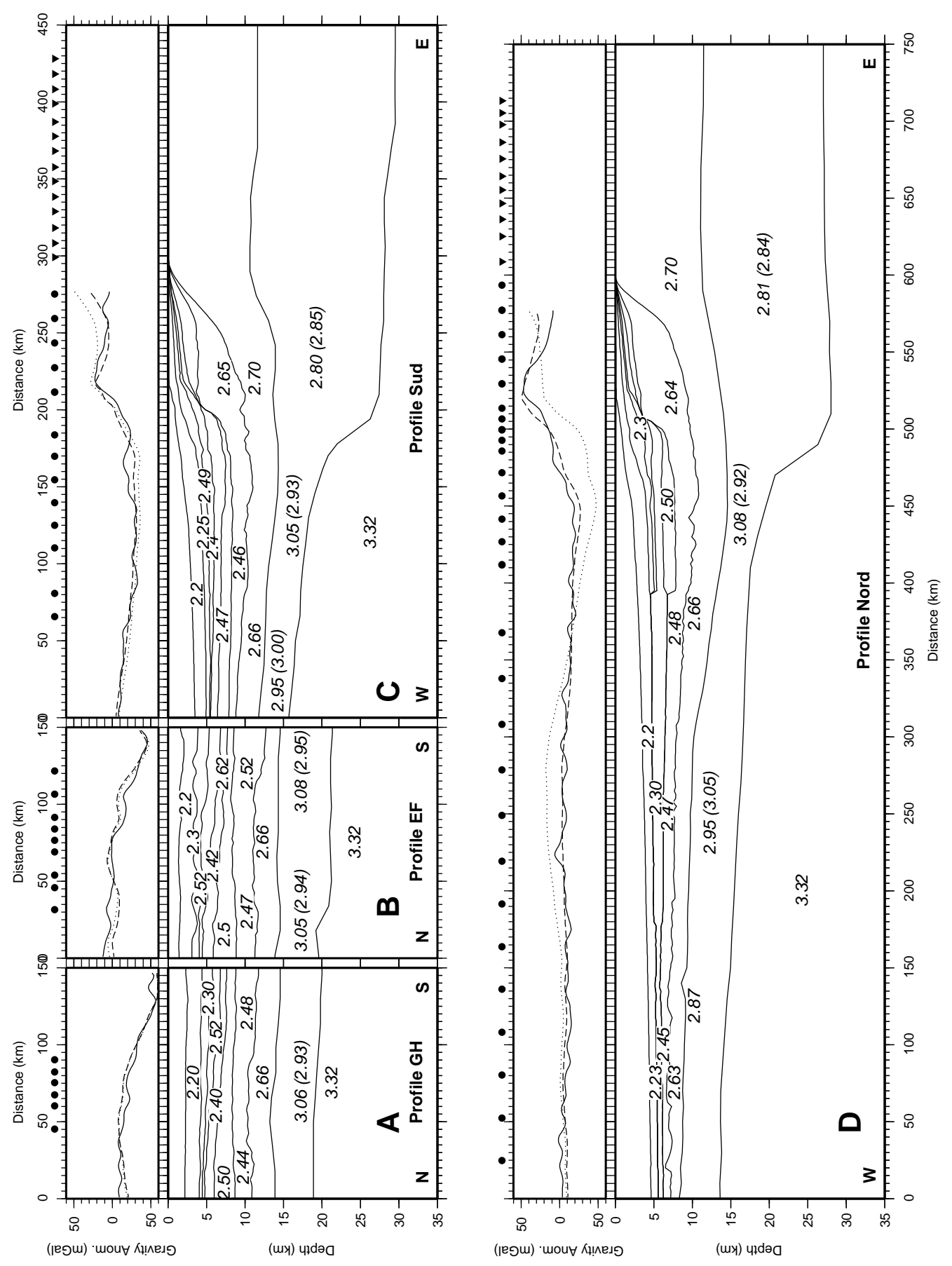

Fig. 16 . 

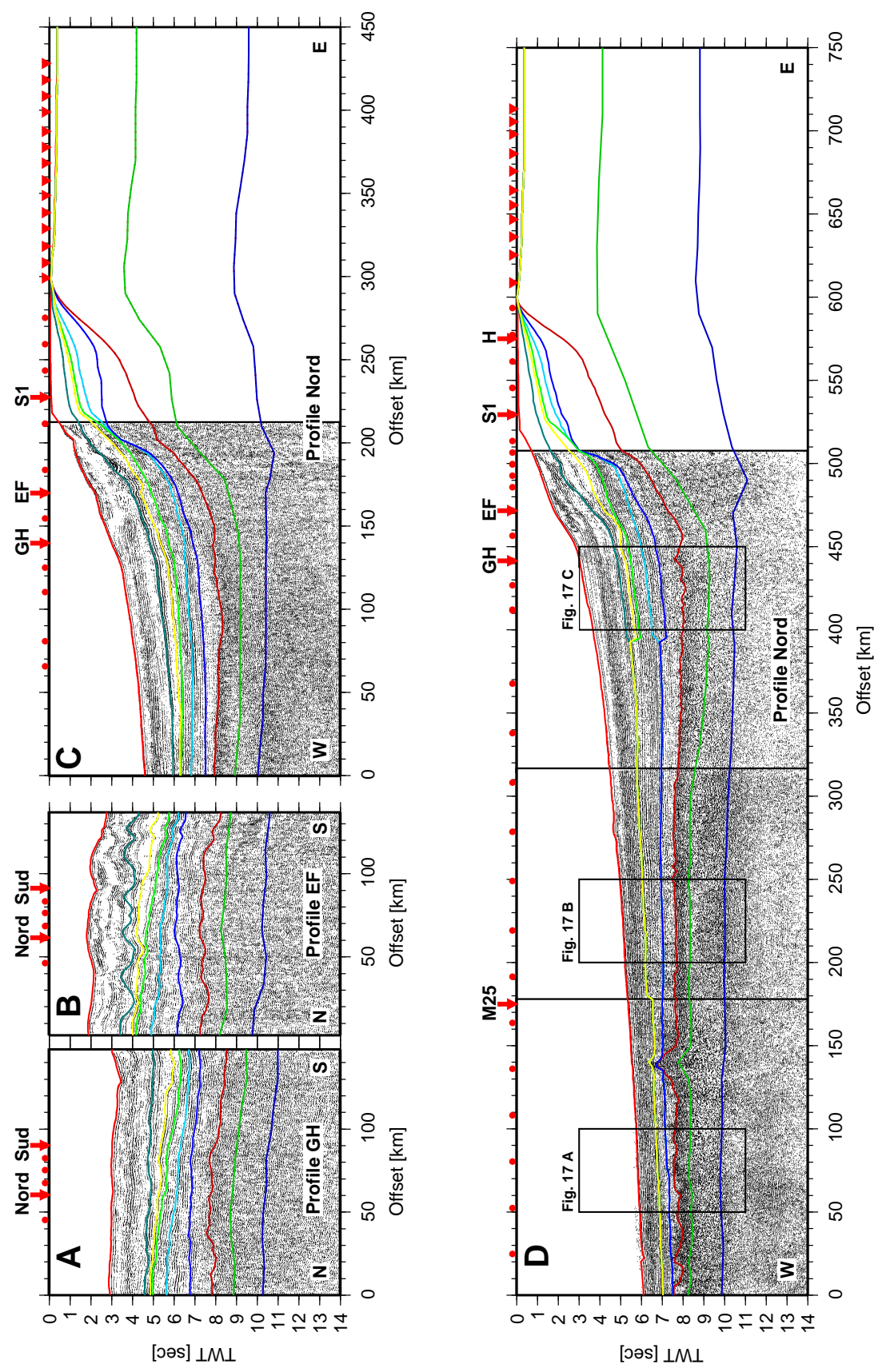

Fig. 17. 

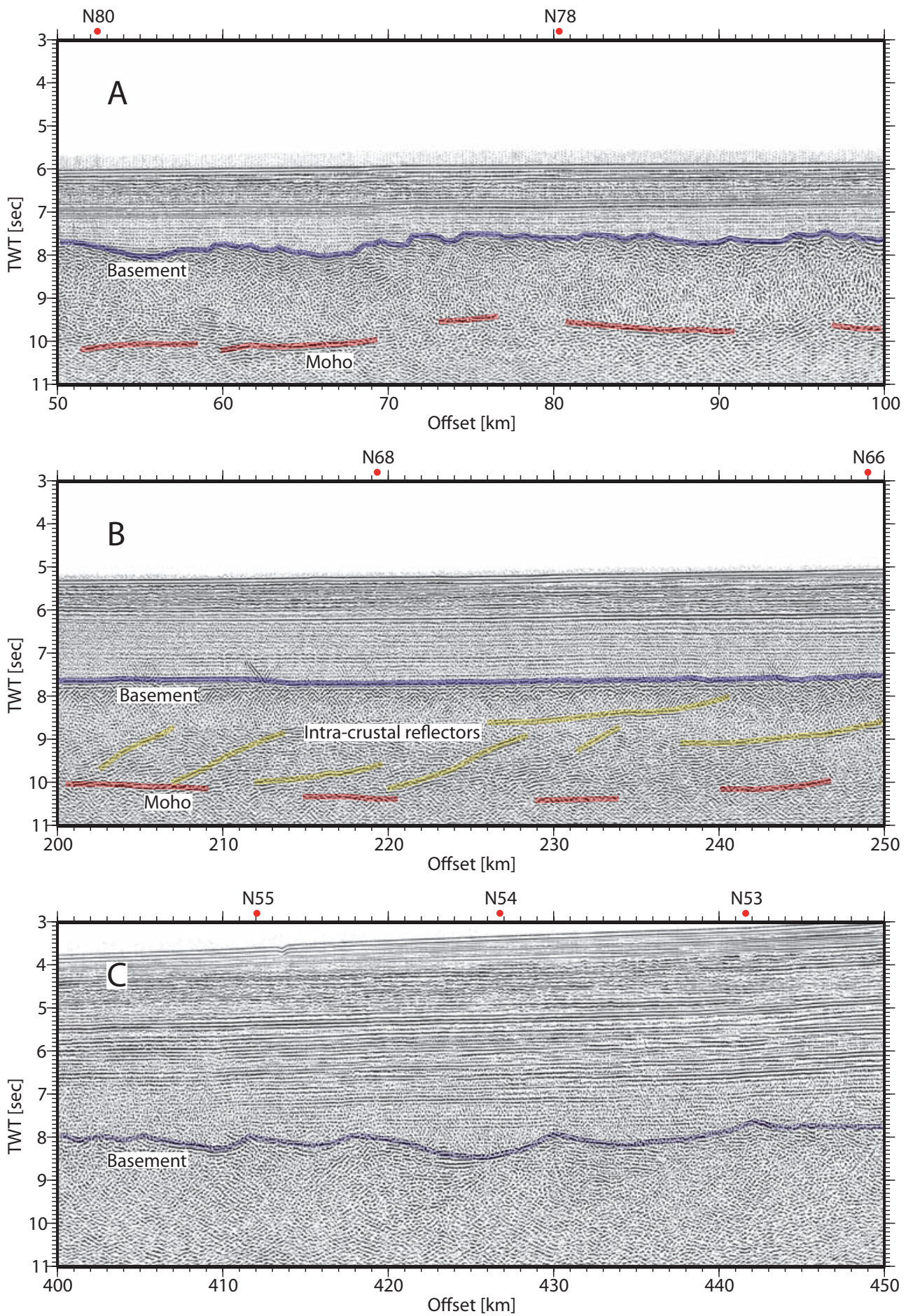

Fig. 18. 


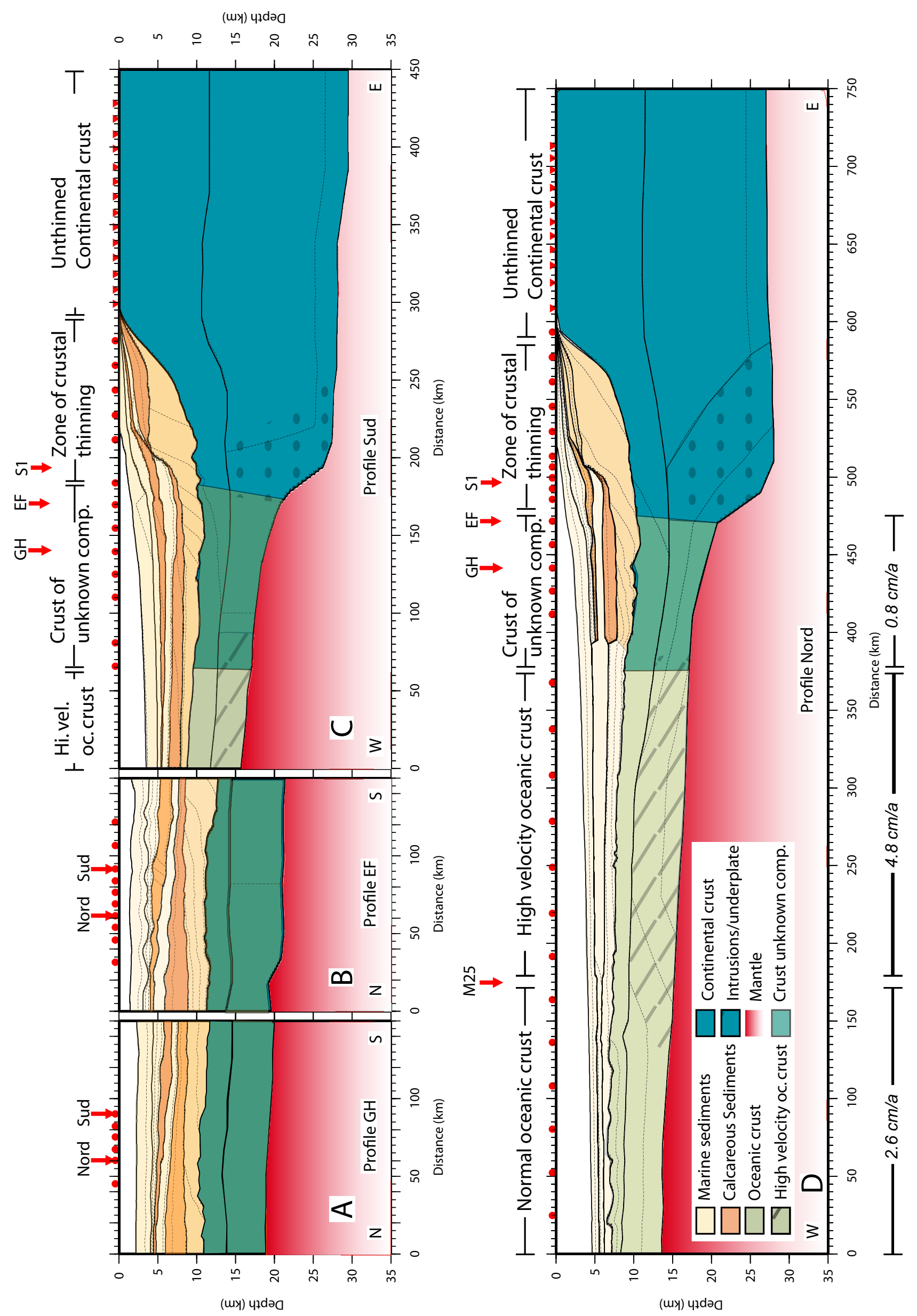

Fig. 19. 


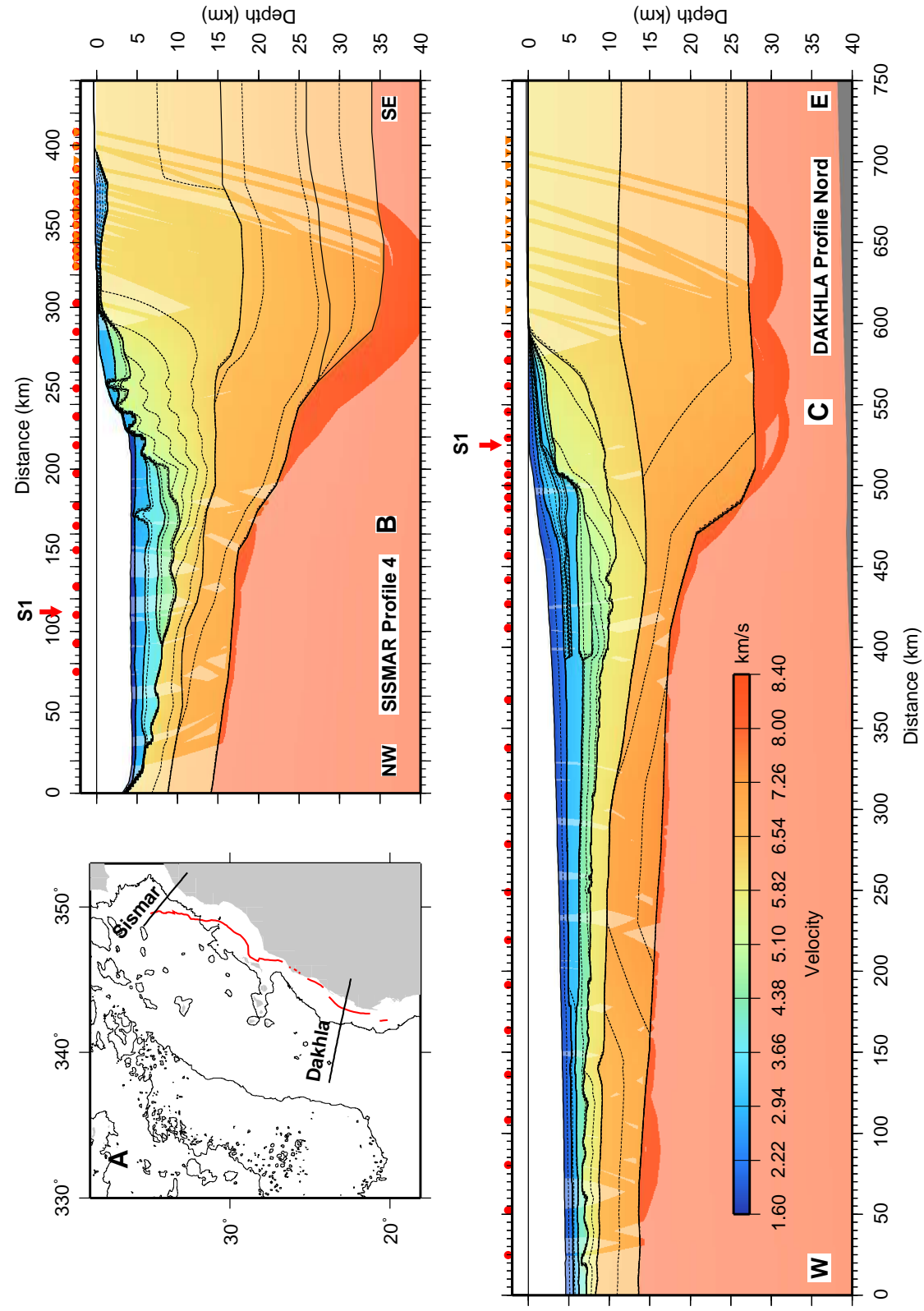

Fig. 20. 